\author{
Robert W. Connell \\ University of Sydney
}

James W. Messerschmidt

University of Southern Maine

\title{
Masculinidade hegemônica: repensando o conceito
}

\begin{abstract}
Resumo: O conceito de masculinidade hegemônica tem influenciado os estudos de gênero em vários campos acadêmicos, mas ao mesmo tempo tem atraído um sério criticismo. Os autores traçam a origem do conceito a uma convergência de ideias no início dos anos 1980 e mapeiam as formas através das quais o conceito foi aplicado quando os estudos sobre homens e masculinidades se expandiram. Avaliando as principais críticas, os autores defendem o conceito de masculinidade como fundamental, uma vez que, na maioria das pesquisas que o opera, seu uso não é reificador nem essencialista. Entretanto, as críticas aos modelos assentados em características de gênero e às tipologias rígidas são sólidas. O tratamento do sujeito em pesquisas sobre masculinidades hegemônicas pode ser melhorado com a ajuda dos recentes modelos psicológicos, mesmo que os limites à flexibilidade discursiva devam ser reconhecidos. O conceito de masculinidade hegemônica não equivale a um modelo de reprodução social; precisam ser reconhecidas as lutas sociais nas quais masculinidades subordinadas influenciam formas dominantes. Por fim, os autores revisam o que foi confirmado por formulações iniciais (a ideia de masculinidades múltiplas, o conceito de hegemonia e a ênfase na transformação) e o que precisa ser descartado (tratamento unidimensional da hierarquia e concepções de características de gênero). Os autores sugerem a reformulação do conceito em quatro áreas: um modelo mais complexo da hierarquia de gênero, enfatizando a agência das mulheres; o reconhecimento explícito da geografia das masculinidades, enfatizando a interseccionalidade entre os níveis local, regional e global; um tratamento mais específico da encorporação ${ }^{1}$ em contextos de privilégio e poder; e uma maior ênfase na dinâmica da masculinidade hegemônica, reconhecendo as contradições internas e as possibilidades de movimento em direção à democracia de gênero. Palavras-chave: masculinidade; hegemonia; gênero; poder social; agência; encorporação; globalização.
\end{abstract}

Copyright (c) 2013 by Revista Estudos Feministas.

${ }^{1} \mathrm{~N}$. T.: termo utilizado para traduzir a categoria "embodiment" usada pelos autores.

${ }^{2}$ Este artigo foi publicado original-
O conceito de masculinidade hegemônica formulado há duas décadas influenciou consideravelmente o pensamento atual sobre homens, gênero e hierarquia social. ${ }^{2}$ Esse conceito possibilitou uma ligação entre o campo em crescimento dos estudos sobre homens (também conhecidos 
mente na revista Gender \& Society v. 19, n. 6, p. 829-859, Dec. 2005.

${ }^{3}$ DINGES, RÜNDAL e BAUER, 2004.

4 e.g., DEMETRIOU 2011; e WETHERELL Q EDLEY, 1999.

\footnotetext{
${ }^{5}$ KESSLER et al., 1982.

${ }^{\circ}$ Raewyn CONNELL, 1983.

${ }^{7}$ CONNELL, 1982.

${ }^{8}$ CONNELL et al., 1982.

9 CARRIGAN, CONNELL e LEE 1985.
}

como estudos de masculinidade e estudos críticos dos homens), ansiedades populares sobre homens e meninos, posição feminista sobre o patriarcado e modelos sociais de gênero. Encontrou uso em campos aplicados que variam desde a educação ao trabalho antiviolência até a saúde e o aconselhamento.

Pesquisas em bancos de dados mostram mais de 200 artigos que usam o termo exato "masculinidade hegemônica" em seus títulos ou resumos. Artigos que usam uma variante ou que se referem à "masculinidade hegemônica" no texto chegam a centenas. Um interesse contínuo é visto em conferências. No início de maio de 2005, a conferência "Masculinidade hegemônica e política internacional" ocorreu na Universidade de Manchester, Inglaterra; em 2004, uma conferência interdisciplinar em Stuttgart focou no tópico "Hegemoniale Männlichkeiten".3

O conceito também atraiu um sério criticismo de várias direções: sociológico, psicológico, pós-estruturalista e materialista. ${ }^{4}$ Fora do meio acadêmico foi atacado como para citar um post com grande repercussão na internet "uma invenção dos psicólogos New Age" determinados a mostrar que os homens são muito machos.

Esse é um conceito contestado. Ao mesmo tempo, os assuntos de que trata continuam presentes nas lutas contemporâneas sobre poder e liderança política, violência pública e privada, transformações na família e na sexualidade. Uma reavaliação compreensiva do conceito de masculinidade hegemônica parece valer a pena. Caso prove ser útil, o conceito deve ser reformulado em termos contemporâneos. Almejamos ambas as tarefas neste artigo.

\section{Origem, formulação e aplicação Origem}

O conceito de masculinidade hegemônica foi primeiro proposto em relatórios de um estudo de campo sobre desigualdade social nas escolas australianas; 5 em uma discussão conceitual relacionada à construção das masculinidades e à experiência dos corpos de homens; ${ }^{6} \mathrm{e}$ em um debate sobre o papel dos homens na política sindical australiana. ${ }^{7} \mathrm{O}$ projeto nas escolas forneceu a evidência empírica de múltiplas hierarquias - de gênero e ao mesmo tempo de classe - entrelaçadas com projetos ativos de construção do gênero. ${ }^{8}$

Os estudos pioneiros foram sistematizados no artigo "Towards a New Sociology of Masculinity", 9 que criticou extensivamente a literatura sobre o "papel sexual masculino" e propôs um modelo de masculinidades em múltiplas 
${ }^{10}$ CONNELL, 1987.

"GOODE, 1982; e SNODGRASS 1977.

12 TOLSON, 1977

${ }^{13}$ Maxine Baca ZINN, 1982.

${ }^{14}$ Angela DAVIS, 1983

${ }^{15}$ Bell HOOKS, 1984.

16 CONNELL, 1977.

17 EISENSTEIN, 1979

${ }^{18}$ HACKER, 1957.

19 BRANNON, 1976 relações de poder. Por sua vez, o modelo foi sistematicamente integrado a uma teoria de gênero sociológica. As seis páginas resultantes em Gender and Power ${ }^{10}$ sobre "masculinidade hegemônica e feminilidade enfatizada" se tornaram a fonte mais citada para o conceito de masculinidade hegemônica.

O conceito articulado por grupos de pesquisa australianos representou a síntese de ideias e evidência de fontes aparentemente díspares. Mas a convergência de ideias não foi acidental. Assuntos intimamente ligados foram sendo tratados por pesquisadores e ativistas também em outros países; o tempo era, em certo sentido, maduro para uma síntese dessa natureza.

As fontes mais básicas foram as teorias feministas do patriarcado e os debates sobre o papel dos homens na transformação do patriarcado. " Alguns homens da nova esquerda tentaram se organizar em apoio ao feminismo, e essa tentativa chamou atenção para as diferenças de classe na expressão da masculinidade. ${ }^{12}$ Além disso, as mulheres de cor - tais como Maxine Baca Zinn, ${ }^{13}$ Angela Davis ${ }^{14}$ e Bell Hooks $^{15}$ - criticaram os preconceitos raciais que ocorrem quando o poder é unicamente conceitualizado em termos de diferenças de sexo, preparando, desse modo, o terreno para o questionamento de quaisquer reivindicações universalizantes sobre a categoria de homem.

O termo gramsciniano de "hegemonia" foi corrente, no período, em tentativas de compreender a estabilização das relações de classe. ${ }^{16}$ No contexto da teoria dos sistemas duais, ${ }^{17}$ a ideia foi facilmente transferida para o problema paralelo das relações de gênero. Essa transferência teve significativo risco de mal entendimento. Os escritos de Gramsci focam nas dinâmicas da mudança estrutural envolvendo a mobilização e a desmobilização de classes inteiras. Sem um foco claro nesse tópico da mudança histórica, a ideia de hegemonia teria sido reduzida a um modelo simples de controle cultural. E, em boa parte do debate sobre gênero, a mudança histórica em larga escala não está em foco. Aqui vemos uma das fontes das últimas dificuldades com o conceito de masculinidade hegemônica.

Mesmo antes do Movimento de Liberação das Mulheres, a literatura sobre o "papel sexual do homem" na psicologia social e na sociologia reconheceu a natureza social da masculinidade e as possibilidades de transformação da conduta dos homens. ${ }^{18}$ Ao longo dos anos 1970 houve uma explosão de escritos sobre o "papel masculino", nitidamente criticando as normas sobre papéis como origem do comportamento opressivo dos homens. ${ }^{19} \mathrm{~A}$ crítica à teoria dos papéis forneceu a base conceitual principal para o primeiro movimento de homens antissexistas. A debilidade da teoria 
${ }^{20}$ KIMMEL 1987; e PLECK, 1981.

${ }^{21}$ ALTMAN, 1972.

${ }^{22}$ MIELI, 1980.

${ }^{23}$ MORIN E GARFINKLE, 1978.

${ }^{24}$ BROKER, 1976; P PLUMMER 1981.

${ }^{25}$ WILLIS, 1977.

${ }^{26}$ COCKBURN, 1983.

${ }^{27}$ HERDT, 1981; e HUNT, 1980.

${ }^{28}$ FREUD, 1955

29 STOLLER, 1968.

30 FRIEDMAN E LERNER, 1986; e ZARETSKY, 1975. dos papéis sexuais foi, entretanto, cada vez mais reconhecida. ${ }^{20}$ Esses autores incluíram a desfocagem característica do comportamento e da norma, o efeito homogeneizador do conceito de papel e suas dificuldades em acessar o poder? Considerar a questão do poder? Dar conta da questão do poder? Incorporar a concepção de poder?

Por outro lado, o poder e a diferença foram conceitos centrais no movimento de liberação gay, o qual desenvolveu uma análise sofisticada da opressão do homem, assim como da opressão pelo homem. ${ }^{21}$ Alguns teóricos perceberam a liberação gay como ligada a um ataque aos estereótipos de gênero. ${ }^{22} \mathrm{~A}$ ideia de uma hierarquia das masculinidades cresceu diretamente a partir da experiência de homens homossexuais com a violência e com o preconceito dos homens heterossexuais. O conceito de homofobia originouse nos anos 1970 e já estava sendo atribuído ao papel masculino convencional. ${ }^{23}$ Teóricos desenvolveram contribuições cada vez mais sofisticadas sobre as relações ambivalentes entre os homens gays e o patriarcado e com a masculinidade convencional. ${ }^{24}$

Uma fonte igualmente importante foi a pesquisa social empírica. Um corpus em crescimento de estudos de campo estava documentando hierarquias locais de gênero e culturas locais de masculinidades nas escolas, ${ }^{25} \mathrm{em}$ locais de trabalho dominados por homens ${ }^{26}$ e em comunidades populares. ${ }^{27}$ Esses estudos acrescentaram 0 realismo etnográfico de que a literatura de papéis sexuais carecia, confirmando a pluralidade de masculinidades e as complexidades da construção do gênero para os homens, e trazendo evidências à luta ativa pela dominância, que é implícita ao conceito gramsciniano de hegemonia.

Por fim, o conceito foi influenciado pela psicanálise. O próprio Freud produziu a primeira análise de biografias de homens e, na história do caso do "Homem dos Lobos", mostrou como a personalidade adulta era um sistema sob tensão, com contracorrentes reprimidas, mas não obliteradas. ${ }^{28} \mathrm{O}$ psicanalista Stoller ${ }^{29}$ popularizou o conceito de "identidade de gênero" e mapeou suas variações no desenvolvimento de meninos, sendo as mais famosas aquelas que levam ao transexualismo. Outros autores influenciados pela psicanálise dedicaram-se aos temas do poder dos homens, do espectro de possibilidades do desenvolvimento do gênero e da tensão e contradição dentre masculinidades convencionais. ${ }^{30}$

\section{Formulação}

O que emergiu dessa matriz em meados dos anos 1980 foi análogo, em termos de gênero, às pesquisas na 
sociologia sobre estruturas de poder, dando centralidade ao grupo dominante. A masculinidade hegemônica foi entendida como um padrão de práticas (i.e., coisas feitas, não apenas uma série de expectativas de papéis ou uma identidade) que possibilitou que a dominação dos homens sobre as mulheres continuasse.

A masculinidade hegemônica se distinguiu de outras masculinidades, especialmente das masculinidades subordinadas. A masculinidade hegemônica não se assumiu normal num sentido estatístico; apenas uma minoria dos homens talvez a adote. Mas certamente ela é normativa. Ela incorpora a forma mais honrada de ser um homem, ela exige que todos os outros homens se posicionem em relação a ela e legitima ideologicamente a subordinação global das mulheres aos homens.

Homens que receberam os benefícios do patriarcado sem adotar uma versão forte da dominação masculina podem ser vistos como aqueles que adotaram uma cumplicidade masculina. Foi em relação a esse grupo, e com a complacência dentre as mulheres heterossexuais, que o conceito de hegemonia foi mais eficaz. A hegemonia não significava violência, apesar de poder ser sustentada pela força; significava ascendência alcançada através da cultura, das instituições e da persuasão.

Esses conceitos eram abstratos em vez de descritivos, definidos em termos da lógica do sistema patriarcal de gênero. Assumiam que as relações de gênero eram históricas e, dessa forma, as hierarquias de gênero eram sujeitas a mudanças. Nesse sentido, as masculinidades hegemônicas passaram a existir em circunstâncias específicas e eram abertas à mudança histórica. Mais precisamente, poderia existir uma luta por hegemonia e formas anteriores de masculinidades poderiam ser substituídas por novas. Esse foi um elemento de otimismo numa teoria de outra forma bastante sombria. Talvez fosse possível que uma maneira de ser homem mais humana, menos opressiva, pudesse se tornar hegemônica como parte de um processo que levaria à abolição das hierarquias de gênero.

\section{Aplicação}

O conceito de masculinidade hegemônica, formulado nesses termos, encontrou uso imediato. No final dos anos 1980 e início dos anos 1990, pesquisas sobre homens e masculinidade estavam se consolidando como um campo acadêmico, apoiado por uma série de conferências, pela publicação de livros ${ }^{31}$ e revistas acadêmicas, e rapidamente expandiu a agenda de pesquisas nas ciências sociais e humanidades. 


\section{MARTINO, 1995. \\ ${ }^{33}$ SKELTON, 1993.}

${ }^{34}$ MESSERSCHMIDT, 1993.

${ }^{35}$ NEWBURN E STANKO, 1994.

${ }^{36}$ JANSEN E SABO, 1994.

${ }^{37}$ HANKE, 1992.

${ }^{38}$ MESSNER, 1992.

${ }^{39}$ MESSNER E SABO, 1990.

${ }^{40} \mathrm{~N}$. T.: no original "playing hurt", expressão de língua inglesa usada para várias situações em que o sujeito, mesmo lesionado ou com dor, dá continuidade a determinada prática. Expressão muito ligada aos esportes e às práticas sexuais masculinas.

${ }^{41}$ SABO e GORDON, 1995.

${ }_{42}$ GERSCHICK E MILLER, 1994.
O conceito de masculinidade hegemônica foi usado em estudos na educação para compreender as dinâmicas da vida em sala de aula, incluindo os padrões de resistência e bullying entre meninos. Foi usado para explorar as relações com o currículo e as dificuldades da pedagogia neutra de gênero. ${ }^{32}$ Foi usado para entender as estratégias e as identidades de professores em grupos, tais como os de instrutores de educação física. ${ }^{33}$

O conceito também influenciou a criminologia. Todos os dados refletiam que os homens e os meninos perpetravam mais os crimes convencionais - e os mais sérios desses crimes - que as mulheres e as meninas. Para além, os homens mantinham um monopólio virtual sobre determinadas formas de crime, como crimes em sindicatos e crimes de colarinhobranco. O conceito de masculinidade hegemônica contribuiu na teorização da relação entre masculinidades e uma série de crimes, ${ }^{34}$ e foi também usado em estudos sobre crimes específicos de homens e meninos, tais como estupro na Suíça, assassinato na Austrália, hooliganismo no futebol americano e crimes do colarinho-branco na Inglaterra, além da agressão violenta nos Estados Unidos. ${ }^{35}$

O conceito também foi usado nas pesquisas sobre as representações do homem na mídia, por exemplo, nas interconexões entre o esporte e os imaginários de guerra. ${ }^{36}$ Como o conceito de hegemonia ajudou a dar sentido tanto à diversidade como à seletividade das imagens na mídia de massa, os estudiosos da mídia começaram a mapear as relações entre diferentes representações de masculinidades. ${ }^{37}$ Esportes comerciais são um foco das representações midiáticas da masculinidade, e o campo em desenvolvimento da sociologia do esporte também encontrou um uso significativo do conceito de masculinidade hegemônica. ${ }^{38}$ Foi implantado na compreensão da popularidade dos esportes de contato e confronto - que funcionam como uma renovação contínua do símbolo da masculinidade - e na compreensão da violência e homofobia frequentemente presentes em meios esportivos. ${ }^{39}$

Os determinantes sociais da saúde dos homens foram levantados anteriormente, mas o conceito de papel sexual estava muito difuso para ser considerado útil. Os conceitos de múltiplas masculinidades e de masculinidade hegemônica foram progressivamente mais usados para compreender as práticas de saúde dos homens, tais como "jogar ferido" ${ }^{40}$ e comportamentos que envolvem risco ${ }^{41}$ Os conceitos de masculinidade hegemônica e subordinada ajudaram a compreensão da exposição dos homens a situações de risco, como também acerca de suas dificuldades para lidar com as próprias incapacidades e ferimentos. ${ }^{42}$ 
${ }^{43}$ CHENG, 1996; e COCKBURN, 1991.

${ }^{44}$ MESSERSCHMIDT, 1995.

${ }^{45}$ BARRETT, 1996.

${ }^{46}$ KUPERS, 1993.

47 DENBOROUGH, 1996.

${ }^{48}$ SALISBURY E JACKSON, 1996.
${ }^{53}$ BUFKIN, 1999; e MESSERSCHMIDT, 1997

${ }^{54}$ MESSNER, 1992.
O conceito de masculinidade hegemônica também se mostrou significativo nos estudos organizacionais, em que o caráter generificado das burocracias e dos locais de trabalho foi cada vez mais reconhecido. Estudos etnográficos e com entrevistas traçaram a institucionalização das masculinidades hegemônicas em organizações específicas ${ }^{43}$ e seu papel nos processos organizacionais de tomada de decisões. ${ }^{44} \mathrm{Um}$ foco particular dessas pesquisas foi a instituição militar, em que padrões específicos de masculinidade hegemônica costumam ser dominantes, mas têm se tornado cada vez mais problemáticos. ${ }^{45}$

Discussões sobre prática profissional envolvendo homens e meninos também utilizaram o conceito. Tais práticas incluem a psicoterapia com homens, ${ }^{46}$ programas de prevenção à violência para a juventude ${ }^{47}$ e programas de educação emocional para meninos. ${ }^{48}$

Esses foram os campos primários em que o conceito de masculinidade hegemônica foi aplicado na década posterior à sua formulação. Mas também houve uma vasta gama de aplicação, em discussões de arte, ${ }^{49}$ por exemplo, em disciplinas acadêmicas como Geografia ${ }^{50}$ e Direito, ${ }^{51}$ e em discussões mais gerais sobre as políticas de gênero dos homens e a relação com o feminismo. ${ }^{52}$ Podemos razoavelmente concluir que a análise das múltiplas masculinidades e o conceito de masculinidade hegemônica serviram como quadro para muitos dos esforços das pesquisas em desenvolvimento sobre homens e masculinidade, substituindo a teoria do papel sexual e os modelos categoriais da psiquiatria.

Eventualmente os esforços em crescimento de pesquisas tendiam a expandir o conceito. Essa imagem pode ser vista em quatro formas principais: pela documentação sobre as consequências e os custos da hegemonia, pelo desvelamento dos mecanismos da hegemonia, pela demonstração da vasta diversidade de masculinidades e pelo delineamento das transformações nas masculinidades hegemônicas.

No que tange aos custos e às consequências, pesquisas em criminologia mostraram como padrões particulares de agressão eram ligados com a masculinidade hegemônica, não como um efeito mecânico do qual ela fosse a causa, mas através da busca pela hegemonia. ${ }^{53}$ Além disso, a pesquisa pioneira de Messner ${ }^{54}$ mostrou que a colocação em ato da masculinidade hegemônica nos esportes profissionais, ao mesmo tempo que reproduz hierarquias exageradas, também vem com custos consideráveis para os vitoriosos, em termos de danos emocionais e físicos.

Pesquisas têm sido frutíferas na revelação dos mecanismos de hegemonia. Algumas são altamente visíveis, como aquelas sobre a "ostentação" da masculinidade nos 
${ }^{55}$ SABO E JANSEN, 1992.

${ }^{56}$ ROBERTS, 1993.

57 BROWN, 1999.

${ }^{58}$ CONSALVO, 2003.

${ }^{59}$ VALDÉS e OLAVARRÍA, 1998.

${ }^{60}$ ISHII-KUNTZ, 2003.

${ }^{61}$ HIGATE, 2003.

62 GUTMANN, 1996
${ }^{63}$ MORRELL, 1998.

${ }^{64}$ FERGUSON, 2001.

${ }^{65}$ DASGUPTA, 2000.

${ }^{66}$ TAGA, 2003. programas televisivos de esportes, ${ }^{55}$ assim como aquelas sobre mecanismos sociais que Roberts ${ }^{56}$ chama de "censura" direcionada a grupos subordinados - variando desde xingamentos informais por crianças à criminalização da conduta homossexual. Ainda outros mecanismos de hegemonia operam por invisibilidade, removendo a forma dominante da masculinidade da possibilidade de censura. ${ }^{57}$ Consalvo, ${ }^{58}$ examinando a mídia sobre o massacre na Escola Columbine, nota como a questão da masculinidade foi retirada do escrutínio, deixando a mídia sem outra forma de representar os atiradores, senão como "monstros".

Pesquisas internacionais confirmaram fortemente o insight inicial de que ordens de gênero constroem masculinidades múltiplas. Valdés e Olavarría ${ }^{59}$ mostram que, mesmo em países culturalmente homogêneos como o Chile, não há uma masculinidade unitária, uma vez que os padrões variam por classe e geração. Em outro famoso país homogêneo, o Japão, Ishii-Kuntz" ${ }^{00}$ traça a "emergência de masculinidades diversas" na história social recente, com mudanças nas práticas de cuidado das crianças como desenvolvimento-chave. Diversidade de masculinidades também é encontrada em instituições particulares como a instituição militar. ${ }^{61}$

Gutmann, ${ }^{62}$ na mais bela observação etnográfica moderna da masculinidade, estudou um caso no qual existe uma identidade masculina pública bem definida - o "machismo" mexicano. Ele mostra como o imaginário do machismo se desenvolveu historicamente e foi entrelaçado com o desenvolvimento do nacionalismo mexicano, mascarando a enorme complexidade nas vidas dos homens mexicanos. O autor traz à tona quatro padrões de masculinidade nos ambientes da classe trabalhadora urbana que ele estuda, insistindo que mesmo esses quatro padrões são transversalizados por outras divisões sociais e são constantemente renegociados na vida cotidiana.

Finalmente, um corpo considerável de pesquisas mostra que as masculinidades não são simplesmente diferentes entre si mas também sujeitas a mudanças. Desafios à hegemonia são comuns, e o são também os ajustes em face desses desafios. Morrell ${ }^{63}$ mostra evidências sobre as transformações de gênero na África Meridional associadas com o fim do Apartheid, um sistema de patriarcados segregados e concorrentes. Ferguson ${ }^{64}$ analisa o declínio dos ideais de longa duração de masculinidade na Irlanda - o padre celibatário e o homem de família que trabalha duro - e sua substituição por modelos mais modernizados e orientados pelo mercado. Dasgupta ${ }^{65}$ pesquisa as tensões no modelo de masculinidade do "assalariado" japonês, especialmente depois da "bolha econômica" dos anos 1980, quando apareceu a figura cultural do "salaryman escaping". Taga ${ }^{66}$ 
${ }^{67}$ MEUSER, 2003.

${ }^{68}$ MORRIS e EVANS, 2001.

${ }^{69}$ COLLINSON E HEARN, 1994.

${ }^{70}$ HEARN, 1996 e 2004.

71 PETERSEN, 1998 e 2003.

72 COLLIER, 1998

${ }^{73}$ MacINNES, 1998. documenta respostas diversas à mudança entre homens jovens da classe média japonesa, incluindo novas opções de parceria doméstica com as mulheres. Meuser ${ }^{67}$ estuda mudanças geracionais na Alemanha, parcialmente dirigidas pelas respostas dos homens às transformações ocorridas com as mulheres. Muitos (apesar de não serem todos) homens jovens, que agora se deparam com a rejeição das mulheres às relações sociais patriarcais, estão elaborando um "igualitarismo pragmático" próprio. Morris e Evans, ${ }^{68}$ estudando imagens da masculinidade e da feminilidade rurais na Grã-Bretanha, encontram um ritmo mais lento na mudança, mas uma sutileza e fragmentação crescentes na representação da masculinidade hegemônica.

Dessa forma, a partir de meados dos anos 1980 até o início dos anos 2000 , o conceito de masculinidade hegemônica passou de um modelo conceitual com uma base empírica bastante restrita para um quadro vasto muito usado nas pesquisas e nos debates sobre homens e masculinidades. O conceito foi aplicado em contextos culturais diversos e a uma gama considerável de questões. Não é surpreendente, então, que o conceito tenha atraído criticismo, aspecto no qual focaremos a partir de agora.

\section{Críticas}

Cinco principais críticas têm sido avançadas desde que o debate sobre o conceito começou no início dos anos 1990. Nesta seção avaliaremos cada crítica esperando descobrir o que vale a pena reter da concepção original de masculinidade hegemônica e o que necessita ser reformulado.

\section{O concelto subjacente de masculinidade}

Que o conceito subjacente de masculinidade é falho já foi argumentado a partir de dois diferentes pontos de vista, realista e pós-estruturalista. Para Collinson e Hearn ${ }^{69}$ e Hearn, ${ }^{70} \mathrm{o}$ conceito de masculinidade é turvo, é incerto no seu significado e tende a desenfatizar questões de poder e dominação. É fundamentalmente desnecessário para a tarefa de compreender e contestar o poder dos homens. O conceito de masculinidades múltiplas tende a produzir uma tipologia estática.

Para Petersen, ${ }^{71}$ Collier ${ }^{72}$ e Maclnnes ${ }^{73}$, o conceito de masculinidade é falho porque ele essencializa o caráter dos homens ou impõe uma unidade falsa a uma realidade fluida e contraditória. Algumas versões desse argumento criticam as pesquisas sobre masculinidades porque essas não adotaram um kit de ferramentas pós-estruturalistas específico - que seria, por exemplo, a ênfase na construção 
${ }^{74}$ WHITEHEAD, 2002.

75 CONNELL, 2003.

76 HALBESRTAM, 1998; e MESSERSCHMIDT, 2004.

77 GUTMANN, 1996.

${ }^{78}$ WARREN, 1997. discursiva das identidades. ${ }^{74} \mathrm{O}$ conceito de masculinidade é criticado por ter sido enquadrado no seio de uma concepção heteronormativa de gênero que essencializa a diferença macho-fêmea e ignora a diferença e a exclusão dentro das categorias de gênero. Ao conceito de masculinidade é atribuído o fato de esse permanecer logicamente numa dicotomização do sexo (biológico) versus gênero (cultural), dessa forma marginalizando ou naturalizando o corpo.

Nenhuma mente responsável pode negar que, em grande parte da literatura preocupada com a masculinidade, há uma grande quantidade de confusão conceitual, assim como uma grande quantidade de essencialização. Isso é certamente comum em abordagens da masculinidade na psicologia pop, na mitopoética do movimento de homens e nas interpretações jornalísticas das pesquisas sobre a diferença biológico-sexual. É uma outra questão, entretanto, reivindicar que o conceito de masculinidade deva ser confundido com essencialismo ou até mesmo que seja tipicamente esse o uso que os pesquisadores fazem do conceito.

Diríamos que as pesquisas sobre masculinidades floresceram em ciências sociais e nas humanidades durante os últimos 20 anos, precisamente porque o conceito subjacente empregado não é reificante ou essencialista. A noção de que o conceito de masculinidade essencializa ou homogeneiza é um tanto quanto difícil de reconciliar com a tremenda multiplicidade das construções sociais que etnógrafos e historiadores têm documentado com o auxílio desse conceito. ${ }^{75} \mathrm{O}$ que distancia o conceito do essencialismo é o fato de que pesquisadores exploraram as masculinidades postas em ato por pessoas com corpos femininos. ${ }^{76} \mathrm{~A}$ masculinidade não é uma entidade fixa encarnada no corpo ou nos traços da personalidade dos indivíduos. As masculinidades são configurações de práticas que são realizadas na ação social e, dessa forma, podem se diferenciar de acordo com as relações de gênero em um cenário social particular.

A ideia de que o reconhecimento de múltiplas masculinidades necessariamente se torna uma tipologia estática também não é confirmada pelo desenvolvimento de pesquisas. Um exemplo paradigmático é a etnografia mexicana de Gutmann, ${ }^{77}$ já mencionada. Gutmann é capaz de desvendar diferentes categorias de masculinidade - por exemplo, o macho e o mandilón -, ao mesmo tempo que reconhece, mostrando em detalhes, que essas não são identidades monádicas, mas sempre relacionais e constantemente transversalizadas por outras divisões e projetos. As observações de Warren ${ }^{78}$ numa escola primária inglesa nos fornecem um outro exemplo. Diferentes construções de 
79 HAWKESWORTH, 1997.

${ }^{80}$ SCOIT, 1997.

${ }^{81}$ CONNELL, 2002; e WALBY, 1997.

${ }^{82}$ CARRIGAN, CONNELL e LEE, 1985.

${ }^{83}$ MESSNER, 1992.

${ }^{84}$ GERSCHICK \& MILLER, 1994.

${ }^{85}$ DONALDSON, 1991.

${ }^{86}$ SABO E GORDON, 1995.

87 MESSERSCHMIDT, 2000.

${ }^{88}$ CONNELL, 1995, cap. 2.

${ }^{89}$ BROD, 1994. masculinidade são encontradas, as quais produzem efeitos na vida da sala de aula, mesmo que muitos meninos não se encaixem exatamente nas categorias principais; de fato, os meninos demonstram relações complexas de aderência e rejeição a essas categorias.

Embora seja atualmente familiar a crítica de que o conceito de gênero traz embutida a heterossexualidade como norma, ${ }^{79}$ essa é uma crítica contestada. ${ }^{80}$ Enquanto identifica corretamente um problema nos modelos categoriais de gênero, não é um criticismo válido dos modelos de gênero relacionais ${ }^{81}$ ou das abordagens históricas em que a construção da categoria de gênero é objeto de investigação. No desenvolvimento do conceito de masculinidade hegemônica, divisões entre os homens - especialmente a exclusão e a subordinação dos homens homossexuais - foram geralmente questões centrais..$^{82} \mathrm{O}$ policiamento da heterossexualidade tem sido um tema recorrente nas discussões sobre masculinidade hegemônica desde então.

A ideia de que o conceito de masculinidade marginaliza ou naturaliza o corpo (porque se supõe que ele se assenta numa dicotomia sexo-gênero) é talvez a mais alarmante das reivindicações dessa crítica. Alarmante porque o atravessamento entre corpos e processos sociais foi um dos temas centrais da pesquisa sobre masculinidades, desde seu início. Um dos primeiros e mais influentes programas de pesquisa no novo paradigma foi a abordagem de Messner ${ }^{83}$ sobre a masculinidade de atletas profissionais, na qual o uso de "corpos como armas" e a permanência de danos nos corpos dos homens foram examinados. A construção da masculinidade em um contexto de incapacidade, ${ }^{84}$ os corpos laborais de homens da classe trabalhadora, ${ }^{85}$ a saúde e a doença dos homens ${ }^{86}$ e a violência interpessoal de meninos $^{87}$ estão dentre os temas de pesquisas que demonstram como os corpos são afetados por processos sociais. Discussões teóricas exploraram a relevância de uma "nova sociologia do corpo" para a construção da masculinidade. ${ }^{88}$

Críticas ao conceito de masculinidade fazem mais sentido quando apontam uma tendência, tanto nas pesquisas como na literatura popular, de dicotomizar as diferenças entre homens e mulheres. Como Brod ${ }^{89}$ precisamente observa, há uma tendência no campo de estudos sobre homens de presumir "esferas separadas", de proceder como se as mulheres não fossem uma parte relevante da análise e, dessa forma, estudar as masculinidades através do olhar exclusivo sobre os homens e sobre as relações entre homens. Como Brod também argumenta, isso não é inevitável. A cura reside em tomar uma abordagem consistentemente relacional do gênero, não em abandonar os conceitos de gênero ou masculinidade. 
90 DONALDSON, 1993.

91 CONNELL, 1990.

${ }^{92}$ MARTIN, 1998.

${ }_{93}$ WETHERELL O EDLEY, 1999.

${ }^{94}$ WHITEHEAD, 1998, p. 58; e 2002, p. 93

\section{Ambiguidade e sobreposição}

As primeiras críticas do conceito levantaram a questão de quem concretamente representa a masculinidade hegemônica. É familiar que muitos homens que detêm grande poder social não encorporam o ideal de masculinidade. Por outro lado, Donaldson ${ }^{90}$ declara que não parecia haver muita substância masculina naqueles homens identificados por pesquisadores como modelos hegemônicos. Ele discute o caso dos surfistas esportivos australianos "iron man" descritos por Connell, ${ }^{91}$ um exemplo popular da masculinidade hegemônica. Mas o status hegemônico regional dos jovens homens na realidade alerta para que eles façam as coisas que seu grupo de pares local define como masculinas - enlouquecer, se mostrar, dirigir bêbado, entrar em uma briga, defender seu próprio prestígio.

Martin $^{92}$ critica o conceito por levar a aplicações inconsistentes, algumas vezes referindo a um tipo fixo de masculinidade e em outras ocasiões referindo ao tipo qualquer que seja dominante em um tempo e em um lugar particulares. Similarmente, Wetherell e Edley ${ }^{93}$ afirmam que o conceito falha na especificação de como a conformidade à masculinidade hegemônica realmente se objetiva na prática. E Whitehead ${ }^{94}$ sugere que há uma confusão sobre quem é realmente um homem hegemonicamente masculino - "É John Wayne ou Leonardo DiCaprio; Mike Tyson ou Pelé? Ou talvez, em diferentes momentos, todos eles?" - e também sobre quem na realidade pode pôr em ato práticas hegemônicas.

Pensamos que os críticos apontaram de forma correta as ambiguidades do uso do conceito. É desejável eliminar qualquer uso da masculinidade hegemônica como fixa, como um modelo trans-histórico. Esse uso viola a historicidade do gênero e ignora a evidência massiva das transformações nas definições sociais da masculinidade.

Mas, em outros aspectos, a ambiguidade em processos de gênero talvez seja importante de ser reconhecida como um mecanismo de hegemonia. Considere-se como uma definição idealizada de masculinidade é constituída em um processo social. Num nível societal mais amplo (ao qual chamaremos de "regional" na continuidade), há uma circulação de modelos de conduta masculina admirável, que são exaltados pelas igrejas, narrados pela mídia de massa ou celebrados pelo Estado. Tais modelos se referem (mas também em vários sentidos as distorcem) às realidades cotidianas da prática social. Um exemplo clássico é a celebração, pelo regime soviético, do trabalhador industrial nomeado Stakhanovite, em homenagem ao minerador de carvão Aleksandr Stakhanov, que, em 1935, bateu o recorde 
${ }^{95}$ DONALDSON, 1993.

96 ROPER, 1994

97 WAJCMAN, 1999.

98 HOCHSCHILD, 1989.

99 MAC AN GHAILL, 1994; THORNE, 1993.

100 CAVENDER, 1999 mundial ao escavar 102 toneladas de carvão em um único dia, provocando uma corrida para bater seu recorde. Parte da distorção aqui foi de que os famosos "trabalhadores de choque" alcançaram seus números com grande ajuda, não reconhecida, de seus colegas de trabalho.

Desse modo, as masculinidades hegemônicas podem ser construídas de forma que não correspondam verdadeiramente à vida de nenhum homem real. Mesmo assim esses modelos expressam, em vários sentidos, ideais, fantasias e desejos muito difundidos. Eles oferecem modelos de relações com as mulheres e soluções aos problemas das relações de gênero. Ademais, eles se articulam livremente com a constituição prática das masculinidades como formas de viver as circunstâncias locais cotidianas. Na medida em que fazem isso, contribuem para a hegemonia na ordem de gênero societal. Não é surpreendente que homens que funcionam como exemplos no nível regional, como os "iron man" discutidos por Donaldson, ${ }^{95}$ exibam contradições.

No nível local, padrões de hegemonia da masculinidade estão embutidos em ambientes sociais específicos, tais como as organizações formais. Existem, por exemplo, padrões bem definidos de masculinidade gerencial nas corporações britânicas estudadas por Roper ${ }^{96}$ e Wajcman. ${ }^{97}$ Modelos hegemônicos de masculinidade socialmente legitimados estão também em jogo nas famílias. Por exemplo, as estratégias de gênero dos homens definem negociações em torno do trabalho doméstico e da "dupla jornada" nas famílias norte-americanas estudadas por Hochschild. ${ }^{98}$ Padrões hegemônicos de masculinidade são tanto envolvidos como contestados, à medida que as crianças crescem. O gênero é produzido nas escolas e nas vizinhanças através de estrutura de grupos de pares, controle do espaço escolar, padrões de encontros afetivossexuais, discursos homofóbicos e assédio. ${ }^{99} \mathrm{Em}$ nenhum desses casos esperaríamos que a masculinidade hegemônica se sobressaísse como um padrão nitidamente definido separado de todos os outros. Um grau de sobreposição e indefinição entre as masculinidades hegemônica e cúmplice é extremamente provável se a hegemonia é efetiva. A sobreposição entre masculinidades também pode ser vista em termos dos agentes sociais construindo masculinidades. Cavender ${ }^{100}$ mostra como os modelos de masculinidade hegemônica foram construídos diferentemente em filmes de longa-metragem nos anos 1940, em comparação com os dos anos 1980. Não é apenas uma questão de personagens descritos em scripts. A prática no nível local - quer dizer, a interação face a face ao filmar um filme como ator - em última análise constrói a fantasia dos modelos de masculinidade hegemônica (nesse caso de 
101 HOLTER, 1997 e 2003.

102 HOLTER, 1997.

${ }^{103}$ HOLTER, 1997 e 2003.

104 BARRETT, 1996.

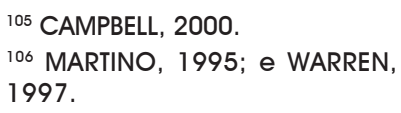

107 COLLIER, 1998. "detetives") no nível societal mais amplo ou no nível regional. (Exploraremos essa questão das relações entre níveis na seção "Revisão e reformulação" deste artigo.)

\section{O problema da reificação}

Que o conceito de masculinidade hegemônica reduza, na prática, a uma reificação do poder ou a uma intoxicação de seu uso também já foi argumentado em diferentes pontos de vista. Holter, ${ }^{101}$ na crítica conceitualmente mais sofisticada de todas, argumenta que o conceito constrói o poder masculino a partir da experiência direta das mulheres em vez da base estrutural da subordinação das mulheres. Holter acredita que nós devemos distinguir entre o "patriarcado", uma estrutura de longo termo da subordinação das mulheres, e o "gênero", um sistema específico de trocas que surgiu no contexto do capitalismo moderno. É um equívoco tratar a hierarquia das masculinidades construídas no seio das relações de gênero como um contínuo lógico com a subordinação patriarcal das mulheres. Holter ${ }^{102}$ significativamente aponta as evidências de um survey norueguês que mostram que as identidades de gênero dos homens não colocam em ato tão prontamente as práticas relacionadas com a igualdade, como o fazem com aquelas relacionadas à violência.

Holter ${ }^{103}$ certamente está certo ao dizer que é um equívoco deduzir relações entre as masculinidades a partir do exercício direto do poder pessoal pelos homens sobre as mulheres. Também devemos levar em questão a institucionalização das desigualdades de gênero, o papel das construções culturais e a ação combinada das dinâmicas de gênero com a raça, a classe e a região.

Na verdade, são as pesquisas sobre essas questões que mostram que o conceito de masculinidade hegemônica não está preso à reificação. No seio dos frutíferos estudos sobre masculinidades institucionais, encontramos aqueles que revelam variações um tanto quanto sutis, por exemplo, entre diferentes ramos de uma força militar, a U.S. Navy. ${ }^{104}$ Há estudos sobre masculinidades hegemônicas locais específicas construídas em espaços como um pub neozelandês, em que vemos o entrelaçamento da masculinidade com a identidade rural. ${ }^{105}$ Outras pesquisas, especialmente aquelas feitas em salas de aula, ${ }^{106}$ mostram a produção refinada e a negociação das masculinidades (e feminilidades) como configurações de prática.

Collier ${ }^{107}$ critica o conceito de masculinidade hegemônica através de seus usos típicos na contabilização da violência e do crime. Na "virada da masculinidade" na criminologia, Collier sugere que a masculinidade hegemônica se tornou associada somente a características negativas que 
${ }^{108}$ MARTIN, 1998, p. 473.

109 MCMAHON, 1993

${ }^{110}$ N. T.: no original "new lad" diz respeito a uma subcultura masculina que surgiu na Inglaterra no início dos anos 1990

11 MOSHER E TOMKINS, 1988.

112 WETHERELL E EDLEY, 1999.

113 COLLIER, 1998. retratam os homens como não emocionais, independentes, não cuidadores, agressivos e não passio-nais - as quais são vistas como causas do comportamento criminal. Martin, 108 similarmente, observa um movimento em direção a uma visão da masculinidade hegemônica não apenas como um tipo, mas como um tipo negativo, por exemplo, ao "dizer que defender o porte de armas é uma defesa da masculinidade hegemônica".

Essa crítica tem força. Ela se assenta na análise precisa de McMahon ${ }^{109}$ sobre o psicologismo em muitas discussões sobre homens e masculinidade. O comportamento dos homens é reificado em um conceito de masculinidade que, em um argumento circular, se torna a explanação (e a desculpa) para o comportamento. Isso pode ser visto em várias discussões sobre a saúde dos homens e os problemas na educação dos meninos - de fato, assim ocorre com qualquer dos problemas contemporâneos definidos sob a consígnia "crise da masculinidade". Na psicologia pop, a invenção de novos tipos de personalidade é endêmica (o macho alfa, o rapaz new age sensível, o homem cabeludo, o novo homem, ${ }^{110} \mathrm{o}$ "homem rato" etc.). Nesse ambiente, a masculinidade hegemônica pode se tornar o sinônimo (com um tom científico) de um tipo de homem rígido, dominador, sexista e "macho" (segundo o uso anglo-saxão, por exemplo). ${ }^{111}$

Devido ao fato de o conceito de masculinidade hegemônica ser baseado na prática que permite a continuidade da dominação coletiva dos homens sobre as mulheres, não é surpreendente que em alguns contextos a masculinidade hegemônica realmente se refira ao engajamento dos homens a práticas tóxicas - incluindo a violência física - que estabilizam a dominação de gênero em um contexto particular. Entretanto, a violência e outras práticas nocivas não são sempre as características definidoras, uma vez que a hegemonia tem numerosas configurações. Para tal, como Wetherell e Edley ${ }^{112}$ ironicamente observam, uma das mais efetivas formas de "ser um homem" em certos contextos locais pode ser a demonstração da distância da masculinidade hegemônica regional.

Collier ${ }^{113}$ vê como um defeito crucial no conceito de masculinidade hegemônica o fato de que esse exclui o comportamento "positivo" por parte dos homens - quer dizer, o comportamento que talvez sirva aos interesses e aos desejos das mulheres. Esse não é um problema uma vez que nós avancemos a marca rígida da teoria da personalidade. Muitas abordagens sobre a masculinidade hegemônica incluem ações "positivas", como trazer para a casa um ordenado, sustentar uma relação sexual e ser um 
114 COLLIER, 1998, p. 21

115 MESSERSCHMIDT, 1993.

116 WETHERELL Q EDLEY, 1999, p. 337. pai. De fato, é difícil enxergar como o conceito de hegemonia seria relevante se apenas as características do grupo dominante fossem a violência, a agressão e o egocentrismo. Tais características talvez signifiquem dominação, mas raramente constituiriam hegemonia - uma ideia que embute certas noções de consenso e participação dos grupos subalternos.

Collier ${ }^{114}$ está certo em comentar que o que está realmente sendo discutido em muitas abordagens da masculinidade hegemônica e do crime (e nós acrescentaremos a saúde e a educação) é "uma gama de ideologias populares do que constitui um ideal ou verdadeiras características do que é 'ser um homem'”. O que falta em Collier, entretanto, é que pesquisas consistentemente sofisticadas prossigam na exploração da relação dessas idealizações com as vidas diárias de meninos e homens - incluindo os desajustes, as tensões e as resistências.

As relações práticas de homens e meninos com as imagens coletivas ou os modelos de masculinidades, em vez de uma simples reflexão sobre elas, são centrais para a compreensão das consequências generificadas nos processos de violência, saúde e educação. Isso tem sido evidente desde que Messerschmidt ${ }^{115}$ formulou a ideia de que diferentes crimes são usados por diferentes homens na construção das masculinidades. Collier considera essa ideia inaceitável, por ser tautológica e universalizante ou excessivamente multitudinal naquilo que explica. Mas não há nada surpreendente sobre a ideia de práticas diversas sendo geradas em modelos culturais comuns; não há nada conceitualmente universalizante sobre a ideia de masculinidade hegemônica. Coordenação e regulação ocorrem nas práticas sociais da vida de coletividades, instituições e sociedades inteiras. O conceito de masculinidade hegemônica não busca abarcar tudo e muito menos ser uma causa primeira; é uma forma de entender certa dinâmica no seio de um processo social.

\section{O sujeito masculino}

Muitos autores têm argumentado que o conceito de masculinidade hegemônica se baseia em uma teoria não satisfatória do sujeito. Wetherell e Edley ${ }^{116}$ desenvolvem essa crítica a partir do ponto de vista da psicologia discursiva, argumentando que a masculinidade hegemônica não pode ser entendida como uma estrutura estabelecida de caráter de qualquer grupo de homens. Devemos questionar "como os homens se acomodam a um ideal e se tornam tipos que são cúmplices e resistentes, sem que qualquer um incorpore exatamente aquele ideal". 
117 WHETHERELL E EDLEY, 1999.

${ }^{118}$ WHITEHEAD, 2002, p. 93

119 WHITEHEAD, 2002, p. 92-94.

${ }^{120}$ COLLIER, 1998; e JEFFERSON 1994, p. 73.
Whetherell e Edley ${ }^{117}$ sugerem que deveríamos compreender as normas hegemônicas como definindo posições de sujeito no discurso que é levado a cabo estrategicamente por homens em circunstâncias particulares. A masculinidade hegemônica tem múltiplos significados - um ponto que alguns autores têm afirmado como uma crítica, mas que Wetherell e Edley tomam como um ponto de partida positivo. Os homens podem se esquivar dentre múltiplos significados de acordo com suas necessidades interacionais. Os homens podem adotar a masculinidade hegemônica quando é desejável, mas os mesmos homens podem se distanciar estrategicamente da masculinidade hegemônica em outros momentos. Consequentemente, a "masculinidade" representa não um tipo determinado de homem, mas, em vez disso, uma forma como os homens se posicionam através de práticas discursivas.

Whitehead ${ }^{118}$ argumenta que o conceito de masculinidade hegemônica "enxerga" apenas a estrutura, tornando o sujeito invisível: "o individual se perde no interior de um aparato ideológico ou, em termos althusserianos, sujeito a ele e a uma vontade inata de poder". Para Whitehead, o conceito falha em especificar como e por que alguns homens heterossexuais legitimam, reproduzem e geram sua dominação e o fazem como uma minoria social vis-à-vis às mulheres e a outros homens. Consequentemente, o uso do conceito resulta em "uma ofuscação, na fusão de masculinidades fluidas com uma estrutura abrangente e, por fim, em uma 'dinâmica estrutural abstrata'". ${ }^{119}$ Para Whitehead, é preferível concentrar no discurso como as formas através das quais os homens conhecem a si mesmos para praticar o "trabalho de identidade" e para exercitar o poder de gênero e a resistência.

Uma crítica relacionada deriva da psicanálise. De acordo com essa visão, o modelo de masculinidade hegemônica presume um sujeito unitário; mas a psicologia profunda revela um sujeito multifacetado e dividido. ${ }^{120}$ Jefferson (2002) critica a "visão excessivamente socializada do sujeito masculino" em estudos de masculinidade, a qual tem resultado em uma falta de atenção sobre como os homens de fato se relacionam psicologicamente com a masculinidade hegemônica. Dadas as múltiplas masculinidades, ele argumenta que pesquisadores deveriam perguntar "como homens concretos, com suas biografias e formações psíquicas particulares, se relacionam com as várias masculinidades". $\mathrm{O}$ autor sugere que meninos e homens escolhem essas posições discursivas que os auxiliam a afastar a ansiedade e evitar sentimentos de ausência de poder.

O argumento da psicologia discursiva é bem aceito e bem integrado com uma abordagem investigativa frutífera. 
${ }^{121}$ LEA E AUBURN, 2001.

122 ARCHER, 2001.

${ }^{123}$ RUBIN, 2003

124 RUBIN, 2003.

125 JEFFERSON, 1994 e 2002
Um bom exemplo é o estudo de Lea e Auburn ${ }^{121}$ sobre a história contada por um estuprador condenado em um programa para infratores sexuais, o qual mostra como o infrator narrador se move entre ideologias conflituosas da interação sexual que, de certa forma, reduzem sua responsabilidade pelo estupro. Outro exemplo é a análise que $\operatorname{Archer}^{122} \mathrm{faz} d a$ fala de jovens homens muçulmanos na Grã-Bretanha sobre identidade, mostrando como eles usam um modelo específico de masculinidade hegemônica ("com ausência de poder patriarcal") para posicionarem-se em relação a homens afro-caribenhos, homens brancos e mulheres muçulmanas. A partir desse trabalho, podemos aprender não apenas como as masculinidades são construídas no discurso, mas também como são usadas no discurso. Especificamente, nós aprendemos como uma versão local da hegemonia da masculinidade pode ser usada para promover o respeito de si diante do descrédito, por exemplo, da difamação racista.

Perspectivas discursivas enfatizam a dimensão simbólica, ao passo que o conceito de masculinidade hegemônica foi formulado dentro de uma compreensão multidimensional do gênero. Embora qualquer especificação da masculinidade hegemônica necessariamente envolva a formulação de ideais culturais, essa não deve ser considerada apenas como uma norma cultural. Relações de gênero também são constituídas através de práticas não discursivas, incluindo trabalho assalariado, violência, sexualidade, trabalho doméstico e cuidado com as crianças, assim como através de ações rotineiras não refletidas.

Reconhecer o não discursivo e as dimensões não refletidas do gênero nos permite perceber alguns sentidos dos limites da flexibilidade discursiva. Que existem tais limites é um ponto forte no estudo de Rubin ${ }^{123}$ sobre homens transexuais feminino-para-masculino. Uma pessoa não é livre para adotar qualquer posição de gênero em interação, simplesmente como um movimento discursivo ou reflexivo. As possibilidades são massivamente limitadas pelos processos de encorporação, pelas histórias institucionais, pelas forças econômicas e pelas relações familiares e pessoais. Os custos de se fazerem determinadas escolhas discursivas podem ser muito altos - como mostrado pelos índices de suicídio dentre pessoas envolvidas em mudanças transexuais.

A coerção também emerge no interior da própria pessoa. Os informantes de Rubin ${ }^{124}$ atuam como o fazem e enfrentam os custos, porque têm uma convicção inabalável de serem homens, apesar de começarem com corpos femininos e terem sido criados como meninas. Eles estão convictos de serem sujeitos unitários, embora vivam uma contradição que Jefferson ${ }^{125}$ parece exemplificar ao 
${ }^{126}$ MESSERSCHIMIDT, 2005.

127 CARRIGAN, CONNELL O LEE, 1985; e CONNELL, 1987.

${ }^{128}$ WHITEHEAD, 2002.

129 CONNELL, 2002.

${ }^{130}$ CONNELL, 1995. argumentar sobre o sujeito dividido. Concordamos com Jefferson que a prática e a teoria psicanalíticas são recursos importantes para a compreensão do sujeito complexo da prática de gênero. Entretanto, a abordagem psicanalítica particular de Jefferson não existe sem problemas, ${ }^{126}$ e é importante reconhecer a diversidade e a riqueza da tradição psicanalítica. Abordagens como a psicanálise existencial de Sartre são úteis na compreensão das masculinidades como projetos e a identidade masculina como tendo sempre sido uma realização provisional no período de uma vida. $A$ psicanálise adleriana, com sua ênfase nas consequências emocionais das relações de poder generificadas na infância, fez emergir a ideia do "protesto masculino", o qual ainda ressoa nas discussões contemporâneas sobre a juventude marginalizada.

O conceito de masculinidade hegemônica foi originalmente formulado com uma forte consciência de argumentos psicanalíticos acerca do caráter multifacetado e contraditório da personalidade, da contestação cotidiana como parte da vida social e da mescla de estratégias necessárias a qualquer tentativa de sustentar a hegemonia. ${ }^{127}$ É um tanto quanto irônico que o conceito seja criticado por simplificar por demais o sujeito, mas com certeza é verdadeiro o fato de que muitas vezes foi empregado de formas simplificadas.

O conceito realmente apaga o sujeito? Nós terminantemente não concordamos com a reivindicação de Whitehead ${ }^{128}$ de que o conceito de masculinidade hegemônica reduz ao determinismo estrutural. A masculinidade é definida como uma configuração de práticas organizadas em relação à estrutura das relações de gênero. A prática social humana cria relações de gênero na história. O conceito de masculinidade hegemônica embute uma visão histórica dinâmica do gênero na qual é impossível apagar o sujeito. É por isso que os estudos de história de vida se tornaram um tipo característico de trabalho sobre masculinidade hegemônica.

O conceito homogeneiza o sujeito apenas se ele é reduzido a uma dimensão única das relações de gênero (usualmente o simbólico) e se ele é tratado como uma especificação da norma. Tão logo se reconheçam a multidimensionalidade das relações de gênero ${ }^{129}$ e a ocorrência das tendências de crise nas relações de gênero, ${ }^{130}$ é impossível perceber o sujeito no seio dessas relações como unitário. Há, claro, diferentes maneiras de se representar a incoerência do sujeito. A linguagem conceitual do pós-estruturalismo é apenas uma forma de fazê-lo; a psicanálise e o modelo da agência no seio de estruturas sociais contraditórias são outras. 
${ }^{131}$ HAWKESWORTH, 1997.

132 BOURDIEU, 2001.
133 BIRD, 1996.

134 COLLINSON, KNIGHTS e COLLINSON, 1990.

135 COCKBURN, 1991

${ }^{136}$ MARTIN, 2001.

\footnotetext{
137 HOOPER, 2001.

138 TOMSEN, 2002.

139 KIMMEL e MAHLER, 2003; e MESSERSCHIMIDT, 2000. N. T.: no original "sissiness".

140 DEMETRIOU, 2001
}

\section{O padrão das relações de gênero}

Nas teorias sociais do gênero, há comumente uma tendência em direção ao funcionalismo - que significa entender as relações de gênero como autônomas, um sistema autorreprodutor e explanatório de todos os elementos em termos de suas funções na reprodução do todo. Hawkesworth ${ }^{131}$ detecta essa tendência na maioria das teorias modernas de gênero e a última intervenção de Bourdieu $^{132}$ para explicar que a dominação masculina deu novo lugar à vida do funcionalismo na análise de gênero.

A dominação dos homens e a subordinação das mulheres constituem um processo histórico, não um sistema autorreprodutor. A "dominação masculina" é aberta à contestação e requer um esforço considerável na sua manutenção. Apesar de se ter dado destaque a esse ponto em declarações iniciais sobre o conceito de masculinidade hegemônica, essa não é apenas uma ideia teórica. Há uma série detalhada de trabalhos que mostram as táticas de manutenção da dominação através da exclusão das mulheres, que variam do trabalho sobre homossociabilidade de Bird $^{133}$ à pesquisa organizacional de Collinson, Knights e Collinson, ${ }^{134}$ Cockburn ${ }^{135}$ e Martin. ${ }^{136}$

Há evidências consideráveis de que a masculinidade hegemônica não é uma forma autorreprodutora, seja através de habitus ou outros mecanismos. Para se sustentar um dado padrão de hegemonia é necessário o policiamento de todos os homens, assim como a exclusão ou o descrédito das mulheres. Evidências de tais mecanismos variam do descrédito de opções "soft" num mundo de relações internacionais "hard", desde as ameaças à segurança e à guerra, ${ }^{137}$ a violências e assassinatos homofóbicos, ${ }^{138}$ chegando aos constrangimentos de meninos nas escolas por "bichices". ${ }^{139}$

Na cuidadosa crítica de Demetriou ${ }^{140}$ sobre o conceito de masculinidade hegemônica, a historicidade do gênero é reconhecida. Ele, entretanto, sugere que outra forma de simplificação tenha ocorrido. Identifica duas formas de hegemonia, interna e externa. A "hegemonia externa" se refere à institucionalização da dominação dos homens sobre as mulheres; e a "hegemonia interna" se refere à ascendência social de um grupo de homens sobre todos os outros homens. $O$ autor argumenta que a relação entre as duas formas é pouco clara na formulação original do conceito e não especificada nos usos correntes. Para além, a hegemonia interna foi entendida como uma forma tipicamente "elitista". Isso quer dizer que masculinidades subordinadas e marginalizadas são vistas como não tendo nenhum impacto na construção da masculinidade 
${ }^{141}$ DEMETRIOU, 2001.

142 DEMETRIOU, 2001, p. 355

143 DEMETRIOU, 2001

${ }^{144}$ DEMETRIOU, 2001

${ }^{145}$ DEMETRIOU, 2001 hegemônica. Masculinidades não hegemônicas existem em tensão com, mas nunca penetram ou impactam a masculinidade hegemônica. Há, então, uma representação dualística das masculinidades.

Tal conceitualização, Demetriou ${ }^{141}$ argumenta, deixa escapar o "pragmatismo dialético" da hegemonia interna, pela qual a masculinidade hegemônica se apropria de outras masculinidades, não importando o quanto pareça pragmaticamente útil na continuidade da dominação. O resultado dessa dialética não é um padrão unitário da masculinidade hegemônica, mas um "bloco histórico" envolvendo uma rede de padrões múltiplos, dos quais o hibridismo é a melhor estratégia possível para a hegemonia externa. Um processo constante em que ocorrem negociação, tradução e reconfiguração.

Essa conceitualização leva a uma visão diferente da transformação histórica nas masculinidades. A masculinidade hegemônica não se adapta simplesmente às condições de transformação histórica. Em vez disso, o bloco masculino hegemônico é uma hibridização cuja apropriação de elementos diversos o faz "capaz de se reconfigurar e adaptar às especificidades de novas conjecturas históricas". ${ }^{142}$ Como um exemplo desse processo, Demetriou $^{143}$ discute o crescimento da visibilidade da masculinidade gay nas sociedades ocidentais. Isso fez com que se tornasse possível para muitos homens heterossexuais se apropriarem de "partes e pedaços" dos estilos e das práticas de homens gays e construírem uma nova configuração híbrida de prática de gênero. Tal apropriação enfumaça a diferença de gênero, mas não enfraquece o patriarcado.

A conceitualização acerca do pragmatismo dialético de Demetriou' ${ }^{144}$ sobre a "hegemonia interna" é útil e constrói uma argumentação convincente de que certas representações da masculinidade e práticas diárias de gênero de alguns homens heterossexuais têm apropriado aspectos das masculinidades gays. Práticas masculinas específicas talvez sejam claramente apropriadas dentro de outras masculinidades, criando um híbrido (como o estilo hip-hop, a linguagem adotada por alguns adolescentes brancos da classe trabalhadora e a composição única de um estilo de "clones" gays). Ainda não estamos convencidos de que a hibridização que Demetriou ${ }^{145}$ descreve seja hegemônica, pelo menos para além de um sentido local. Mesmo que a masculinidade e a sexualidade gay estejam em um processo de crescente visibilidade nas sociedades ocidentais - testemunhado pela fascinação com personagens gays masculinos em programas de televisão como Six Feet Under, Will and Grace e Queer Eye for the 
146 JEFFERSON, 2002, p. 71.

147 MEUSER E BEHNKE, 1998.

148 MESSNER, 1997.
Straight Guy -, há pouca razão em pensar que a hibridização se tornou hegemônica nos níveis regional ou global.

O conceito de um bloco hegemônico traz o foco para a questão de múltiplas masculinidades hegemônicas. Jefferson ${ }^{146}$ e outros têm criticado a tendência de se falar de apenas um padrão - "a masculinidade hegemônica é sempre usada no singular". Há aqui um paradoxo. Devido ao fato de que toda etnografia descobre uma cultura de gênero distinta, de que todo estudo de histórias de vida desvela trajetórias únicas de vidas de homens e de que toda análise estrutural define novas intersecções de raça, classe, gênero e geração, é logicamente possível definir "mil e uma" variações da masculinidade. ${ }^{147}$ Isso também é certamente verdadeiro para os reivindicadores da hegemonia. O ponto é fortemente sustentado pelo mapeamento de Messner ${ }^{148}$ das políticas de masculinidade nos Estados Unidos, que revelou uma gama de movimentos com agendas contrastantes. Ainda quando examinados de perto, muitos desses movimentos apresentam uma reivindicação de serem a maneira correta de como os homens devem pensar e viver. Não importando a diversidade empírica das masculinidades, a contestação pela hegemonia implica que a hierarquia de gênero não possui nichos múltiplos no topo. Voltaremos a essa questão, que é importante para o entendimento das políticas de gênero.

\section{Revisão e reformulação}

Neste momento desenharemos esses tópicos conjuntamente para sugerirmos como o conceito de masculinidade hegemônica deve ser reformulado. Indicaremos aquelas características do conceito original que se sustentaram diante da luz das pesquisas e das críticas, aquelas características que deveriam ser descartadas e, detalhadamente, aquelas áreas em que o conceito necessita de uma reformulação contemporânea.

\section{$O$ que deve ser mantido}

A característica fundamental do conceito continua a ser a combinação da pluralidade das masculinidades e a hierarquia entre masculinidades. Essa ideia básica se manteve firme nos últimos 20 anos de experiência investigativa. Padrões múltiplos de masculinidade têm sido identificados em muitos estudos, em uma variedade de países e em diferentes contextos institucionais e culturais. Também é resultado de pesquisa bastante difundido o fato de que certas masculinidades são socialmente mais centrais ou mais associadas com autoridade e poder social do que outras. $O$ conceito de masculinidade hegemônica presume a subor- 
dinação de masculinidades não hegemônicas, e esse é um processo que agora tem sido documentado em muitos contextos, em nível internacional.

Também muito apoiada é a ideia de que a hierarquia das masculinidades é um padrão de hegemonia, não um padrão de uma hegemonia simples baseada na força. $O$ consenso cultural, a centralidade discursiva, a institucionalização e a marginalização ou a deslegitimação de alternativas são características amplamente documentadas de masculinidades socialmente dominantes. Também muito apoiada é a ideia original de que a masculinidade hegemônica não necessita ser o padrão comum na vida diária de meninos e homens. Em vez disso, a hegemonia trabalha em parte através da produção de exemplos de masculinidade (como as estrelas dos esportes profissionais), símbolos que têm autoridade, apesar do fato de a maioria dos homens e meninos não viver de acordo com eles.

As formulações originais depositaram alguma ênfase na possibilidade de transformação das relações de gênero e na ideia de que um padrão dominante de masculinidade estava aberto à contestação - da resistência das mulheres ao patriarcado, e dos homens como portadores de masculinidades alternativas. Pesquisas confirmaram fortemente a ideia da construção histórica e da reconstrução das masculinidades hegemônicas. Tanto no nível local como nos níveis societais mais amplos, as situações nas quais as masculinidades foram elaboradas mudam ao longo do tempo. Essas mudanças podem suscitar novas estratégias nas relações de poder (por exemplo, os contratos conjugais entre pessoas do mesmo sexo) e resultam em redefinições da masculinidade socialmente admirada (como o parceiro doméstico, em vez do patriarca vitoriano).

\section{O que deve ser rejeltado}

Duas características das formulações iniciais sobre a masculinidade hegemônica não se sustentaram perante as críticas e devem ser descartadas. A primeira é um modelo muito simples das relações sociais em torno das masculinidades hegemônicas. A formulação em Gender and Power se esforçou em localizar todas as masculinidades (e todas as feminilidades) em termos de um padrão único de poder, a "dominação global" dos homens sobre as mulheres. ${ }^{149}$ Na medida em que isso foi útil durante um tempo na prevenção da ideia de múltiplas masculinidades se confrontarem em um conjunto de estilos de vida em competição, agora é claramente inadequado para nosso entendimento das relações entre grupos de homens e formas de masculinidade, e das relações das mulheres com as 
masculinidades dominantes. Por exemplo, a dominação nas relações de gênero envolvem uma interação entre custos e benefícios, desafios à masculinidade hegemônica emergem das "masculinidades de protesto" dos grupos étnicos marginalizados e mulheres burguesas podem se apropriar de aspectos da masculinidade hegemônica ao construírem carreiras profissionais ou corporativas. Claramente, melhores formas de compreender as hierarquias de gênero são necessárias.

Apesar da crítica do traço psicológico em Gender and Power e do apelo às ideias psicanalíticas sobre a motivação inconsciente, declarações iniciais sobre a masculinidade hegemônica, quando tentaram caracterizar o conteúdo de fato das diferentes configurações de masculinidade, muitas vezes caíram numa terminologia classificatória de traços ou na melhor das hipóteses, fracassaram em apresentar alternativas a ela. A noção de masculinidade como um conjunto de traços, que abriu caminho para o tratamento da masculinidade hegemônica como um tipo de caráter fixo, já causou muitos problemas e foi altamente criticada nos escritos psicológicos recentes. Não apenas o conceito essencialista de masculinidade, mas também, em geral, a abordagem dos traços para compreender o gênero necessitam ser completamente transcendidos.

\section{O que deve ser reformulado}

À luz das pesquisas e das críticas discutidas anteriormente, argumentamos que o conceito de masculinidade hegemônica precisa ser reformulado em quatro grandes áreas: a natureza das hierarquias de gênero, a geografia das configurações de masculinidade, o peso do social no processo de encorporação da masculinidade e a dinâmica das masculinidades. Nos subtópicos a seguir ofereceremos uma linha de pensamento e algumas sugestões de pesquisa sobre cada um desses eixos.

\section{Hierarquia de gênero}

Comparadas com as formulações originais do conceito, pesquisas contemporâneas mostraram a complexidade das relações entre diferentes construções da masculinidade. A pesquisa recente em psicologia discursiva indica como diferentes construções da masculinidade no nível local podem servir como alternativas táticas. Relações estruturadas entre masculinidades existem em todos os contextos locais; no entanto, a motivação em direção a uma versão hegemônica específica varia de acordo com o contexto local e tais versões locais de masculinidade inevitavelmente diferem entre si. A noção de Demetriou ${ }^{150}$ de pragmatismo dialético 
151 POYNTING, NOBLE O TABAR, 2003.

152 MESSERSCHMIDT, 2004. captura a influência recíproca das masculinidades umas sobre as outras; padrões de masculinidade hegemônica podem mudar ao incorporarem elementos de outras masculinidades.

Análises das relações entre masculinidades, agora mais claramente, reconhecem a agência dos grupos subordinados e marginalizados - comumente condicionados por sua especificação local (como discutido abaixo). A "Masculinidade de protesto" 151 pode ser entendida neste sentido: um padrão de masculinidade construído em contextos locais de classes trabalhadoras, algumas vezes entre homens etnicamente marginalizados que encorporam a reivindicação de poder típica de masculinidades hegemônicas regionais em países ocidentais, mas carecem de recursos econômicos e autoridade institucional para sustentar os padrões regional e global dessa forma de masculinidade.

Pesquisas também documentaram a durabilidade ou a capacidade de sobrevivência de padrões de masculinidade não hegemônica, os quais podem representar respostas bem trabalhadas à marginalização racial/étnica, à deficiência física, à desigualdade de classe ou à sexualidade estigmatizada. A hegemonia pode se realizar pela incorporação de tais masculinidades em uma ordem de funcionamento do gênero, em vez de uma opressão ativa na forma de descrédito ou violência. Na prática, tanto a incorporação como a opressão podem ocorrer juntas. Isso quer dizer que, por exemplo, a posição contemporânea das masculinidades gays nos centros urbanos ocidentais, onde comunidades gays têm um espectro de experiências variando da violência homofóbica e difamação cultural, à tolerância e mesmo à celebração cultural e à representação política. Processos similares de incorporação e opressão podem ocorrer dentre meninas e mulheres que constroem masculinidades. ${ }^{152}$ O conceito de masculinidade hegemônica foi originalmente formulado em relação ao conceito de feminilidade hegemônica - prontamente renomeada de "feminilidade enfatizada" para reconhecer a posição assimétrica das masculinidades e das feminilidades em uma ordem patriarcal do gênero. No desenvolvimento de pesquisas sobre homens e masculinidades, essa relação saiu de foco. Isso é lastimável por mais de uma razão. O gênero é sempre relacional, e os padrões de masculinidade são socialmente definidos em oposição a algum modelo (quer real ou imaginário) da feminilidade.

Talvez mais importante, focando-se apenas nas atividades dos homens que ocluem as práticas das mulheres na construção do gênero dentre homens. Como é bem mostrado pelas pesquisas com histórias de vida, as mulheres 
são centrais em muitos dos processos de construção das masculinidades - como mães, colegas de classe, namoradas, parceiras sexuais e esposas; como trabalhadoras na divisão sexual do trabalho, e assim por diante. O conceito de feminilidade enfatizada põe o foco sobre a complacência em relação ao patriarcado, e isso continua a ser altamente relevante na cultura de massa contemporânea. Ainda, as hierarquias de gênero também podem ser afetadas pelas novas configurações das identidades e das práticas das mulheres, especialmente mulheres mais jovens - configurações que estão crescentemente sendo reconhecidas pelos homens jovens. Consideramos que as pesquisas sobre masculinidade hegemônica agora precisam estar mais atentas às práticas das mulheres e à ação histórica recíproca entre feminilidades e masculinidades.

Sugerimos, portanto, que nossa compreensão da masculinidade hegemônica precisa incorporar um entendimento mais holístico da hierarquia de gênero, reconhecendo a agência dos grupos subordinados, tanto quanto o poder dos grupos dominantes e o condicionamento mútuo das dinâmicas de gênero e outras dinâmicas sociais. Pensamos que isso tenderá, ao longo do tempo, a reduzir o isolamento dos estudos sobre homens e enfatizará a relevância das dinâmicas de gênero para os problemas - que variam dos efeitos da globalização à questão da violência e da promoção da paz - explorados em outros campos das ciências sociais.

\section{A geografia das masculinidades}

Mudanças em construções locais específicas da masculinidade hegemônica têm sido tema de pesquisas nas duas últimas décadas. Mas a crescente atenção dada à globalização e à significância das arenas transnacionais

153 HOOPER, 1998 e 2000.

154 CONNELL, 1998.

155 PEASE e PRINGLE, 2001

${ }^{156}$ KIMMEL, 2005 para a construção da masculinidade também tem sido argumentada. Hooper ${ }^{153}$ descreve o desenvolvimento da masculinidade hegemônica e de outras formas de masculinidades nas arenas das relações internacionais, e Connell ${ }^{154}$ propõe o modelo da "masculinidade coorporativa transnacional" dentre executivos corporativistas conectados com agendas neoliberais de globalização.

Se, ou o quanto, tais processos ultrapassam dinâmicas de gênero mais locais e regionais, é questão ainda em debate. Pease e Pringle, ${ }^{155}$ em uma coletânea internacional recente, argumentam por um foco contínuo no entendimento regional e comparativo das masculinidades. No mínimo devemos entender que construções regionais e locais da masculinidade hegemônica são conjuradas pela articulação desses sistemas de gênero com processos globais. Nessa veia, Kimmel ${ }^{156}$ examinou recentemente como os efeitos de uma 
masculinidade hegemônica global estão incorporados na emergência de masculinidades "de protesto" regionais (supremacistas brancos nos Estados Unidos e na Suécia) e global (o Al Qaeda do Oriente Médio).

Consideramos que essas questões são agora inevitáveis para os estudos de masculinidade e sugerimos a seguinte estrutura simples. Masculinidades hegemônicas existentes empiricamente podem ser analisadas em três níveis:

1. local: construídas nas arenas da interação face a face das famílias, organizações e comunidades imediatas, conforme acontece comumente nas pesquisas etnográficas e de histórias de vida;

2. regional: construídas no nível da cultura ou do estado-nação, como ocorre com as pesquisas discursivas, políticas e demográficas; e

3. global: construídas nas arenas transnacionais das políticas mundiais, da mídia e do comércio transnacionais, como ocorre com os estudos emergentes sobre masculinidades e globalização.

As ligações entre esses níveis não apenas existem, mas podem ser importantes nas políticas de gênero. Instituições globais pressionam ordens de gênero regionais e locais, ao passo que ordens de gênero regionais fornecem materiais culturais adotados ou retrabalhados em arenas globais e também modelos de masculinidade que podem ser importantes para as dinâmicas de gênero locais.

Consideremos especificamente a relação entre masculinidades regionais e locais. A masculinidade hegemônica no nível regional é simbolicamente representada através da ação recíproca de práticas masculinas locais específicas que têm significância regional, como aquelas construídas por atores de filmes de longa-metragem, por atletas profissionais e por políticos. O conteúdo exato dessas práticas varia ao longo do tempo e nas diferentes sociedades. Ainda, a masculinidade hegemônica regional dá forma a um sentido de realidade masculina em nível societal amplo e, portanto, opera no domínio cultural como material à disposição para ser atualizado, alterado e desafiado através da prática, em uma gama de circunstâncias locais diferentes. Uma masculinidade hegemônica regional fornece, então, uma estrutura cultural que pode ser materializada nas práticas e nas interações cotidianas.

Como uma ilustração dessa ação regional e local recíproca entre masculinidades hegemônicas, consideremos o exemplo do esporte. Nas sociedades ocidentais, as práticas no nível local - como o engajamento em eventos esportivos constroem modelos masculinos hegemônicos ("estrelas do esporte") no nível regional, o qual, em retorno, afeta outras configurações locais. Pesquisas sobre o ensino fundamental 
157 MESSNER, 2002

158 LIGHT e KIRK, 2000.

159 BURGESS, EDWARDS E SKINNER, 2003.

160 MITTELMAN, 2004.

161 CONNELL e WOOD, 2005; e HOOPER, 2001

${ }^{162}$ CONNELL, 2005; O MORRELL $\mathrm{O}$ SWART, 2005 . e médio fornecem um exemplo paradigmático, indicando que a participação bem-sucedida no esporte é comumente uma prática masculina hegemônica em um contexto local particular. ${ }^{157}$ Por exemplo, Light e Kirk ${ }^{158}$ examinaram uma escola de elite australiana, descobrindo que uma clara estrutura de masculinidades existia nessa escola, na qual uma forma hegemônica específica foi conjurada através da prática de encorporação do rugby - um código que certamente não está confinado a essa escola - centrado em dominação, agressão, competição implacável e em dar tudo pela escola. (Comparem-se descobertas similares de Burgess, Edwards e Skinner.) ${ }^{159}$ Desse modo, modelos regionais exemplares influenciam - apesar de não determinarem completamente - a construção das relações de gênero e as masculinidades hegemônicas no nível local.

É tentador assumir uma hierarquia simples de poder e autoridade, circulando do global ao regional e ao local, mas isso poderia levar ao erro. Nas discussões sobre globalização, o poder determinante do "global" é muitas vezes superestimado, ao passo que a resistência e a capacidade daquilo que estamos chamando de "regional" não são reconhecidas. ${ }^{160}$ As limitadas pesquisas que até agora foram feitas sobre masculinidades em arenas globais $^{161}$ não sugerem uma formulação eficaz, com capacidade de prevalecer sobre masculinidades regionais ou locais. Até o momento as evidências sobre dinâmicas globais de gênero estão crescendo, e fica claro que processos como a reestruturação econômica, a migração de longa distância e a turbulência das agendas de "desenvolvimento" têm o poder de remodelar padrões locais de masculinidade e feminilidade. ${ }^{162}$ Temos todas as razões para pensar que as interações envolvendo masculinidades globais irão se tornar cada vez mais importantes nas políticas de gênero e que essa é uma arena-chave para pesquisas futuras sobre hegemonia.

Adotando uma estrutura analítica que distingue as masculinidades nos níveis local, regional e global (e os mesmos pontos se aplicam às feminilidades), podemos reconhecer a importância do território sem cairmos em um mundo monádico de independência cultural e discursiva total. Essa perspectiva também projeta alguma luz no problema das múltiplas masculinidades hegemônicas, levantado anteriormente. Apesar de os modelos locais de masculinidade hegemônica poderem se diferenciar uns dos outros, eles geralmente se sobrepõem. A ação recíproca entre dinâmicas de gênero societais mais amplas é parte da explanação. Além disso, as masculinidades hegemônicas são, em graus significantes, como já argumentamos, constituídas nas interações entre homens e mulheres; portanto, os aspectos 
comuns nas práticas de gênero das mulheres também produzem convergência. Consequentemente, as construções locais da masculinidade hegemônica têm certa "semelhança familiar", para usar um termo de Wittgenstein, em vez de uma identidade lógica. Nesse sentido, a pluralidade local é compatível com a singularidade da masculinidade hegemônica nos níveis regional ou societal amplo. A "semelhança familiar", dentre as variantes locais, é comumente representada por um modelo simbólico no nível regional, nunca por múltiplos modelos.

\section{Encorporação social}

Que a masculinidade hegemônica está relacionada com formas particulares de representação e uso dos corpos dos homens já foi reconhecido desde as formulações iniciais do conceito. Mesmo assim o padrão de encorporação envolvido na hegemonia ainda não foi teorizado de forma convincente.

A importância da encorporação masculina para a identidade e para o comportamento emerge em muitos contextos. Na juventude, as habilidades corporais se tornam um indicador primeiro de masculinidade, conforme vemos no esporte. Essa é uma forma-chave de ligação entre a masculinidade e a heterossexualidade na cultura ocidental, com prestígio dado aos meninos com parcerias heterossexuais e o aprendizado sexual imaginado como exploração e conquista. Práticas corporais, tais como comer carne e assumir riscos na estrada, também se tornam ligadas às identidades masculinas. Logicamente isso resulta na promoção de estratégias de saúde que atuam nos estados de degeneração física - contestando a masculinidade hegemônica ou levando os homens para uma direção mais andrógina. Mas as dificuldades dos processos degenerativos também são parcialmente baseadas na encorporação, como, por exemplo, no compromisso com práticas de risco como significantes para o estabelecimento da reputação masculina em um contexto grupal de pares.

As leituras sobre corpos como objeto de processos de construção social, habituais nas ciências sociais, são agora amplamente consideradas inadequadas. Os corpos estão envolvidos mais ativamente, mais intimamente e mais intrinsecamente em processos sociais do que a teoria usualmente Ihes permitiu. Os corpos participam na ação social ao delinearem os cursos da conduta social - o corpo como participante da geração de práticas sociais. É importante que não apenas as masculinidades sejam entendidas como encorporadas, mas também que sejam tratados os entrelaçamentos das encorporações com os contextos sociais. 
163 RUBIN, 2003

164 NAMASTE, 2000.

${ }^{165}$ RUBIN, 2003, p. 180.

160 CONNELL, 2002

167 DONALDSON E POYNTING, 2004
A necessidade de um tratamento mais sofisticado dos processos de encorporação na masculinidade hegemônica é tornada visível a partir da questão das práticas trans que são difíceis de entender dentro de um modelo simples de construção social. Essa questão foi reformulada pela ascensão da teoria queer, a qual tratou os cruzamentos de gênero como uma subversão da ordem de gênero ou, ao menos, como uma demonstração da sua vulnerabilidade. Debates acalorados sobre o transexualismo emergiram quando alguns psiquiatras levantaram a questão da possibilidade mesma da mudança de gênero. Não é, portanto, fácil estar seguro sobre as implicações da prática trans para a hegemonia. Com Rubin ${ }^{163}$ e Namaste, ${ }^{164}$ consideramos que as masculinidades construídas durante as vidas de pessoas transexuais fêmea-para-macho não são inerentemente contra-hegemônicas. "Homens feitos por si próprios" podem buscar a igualdade de gênero ou se oporem a ela, como qualquer homem não transexual. $O$ que a experiência transexual destaca é a forma como a modernidade trata o corpo como um "meio através do qual indivíduos interagem uns com os outros". ${ }^{165}$

Para entender a encorporação e a hegemonia, precisamos compreender que os corpos são tanto objetos da prática social como agentes na prática social. ${ }^{166}$ Existem circuitos de práticas sociais ligando processos corporais e estruturas sociais - muitos desses circuitos se somam ao processo histórico no qual a sociedade é encorporada. Esses circuitos de encorporação social podem ser muito diretos ou simples, ou podem ser longos e complexos, passando por instituições, relações econômicas, símbolos culturais, e assim por diante - não cessando de envolver os corpos materiais. Isso pode ser facilmente ilustrado ao pensarmos sobre os padrões de gênero na saúde, na doença, no tratamento médico.

Dentre grupos dominantes de homens, os circuitos de encorporação social constantemente envolvem as instituições nas quais seus privilégios permanecem. Isso é dramaticamente visto no estudo pioneiro de Donaldson e Poynting ${ }^{167}$ sobre as vidas cotidianas de homens da classe dominante. Esse estudo mostra, por exemplo, como os esportes característicos, as práticas de lazer e a alimentação desses homens publicizam sua riqueza e estabelecem relações de distância e dominação sobre os corpos de outros homens. Um campo rico de pesquisa se abre aqui, especialmente quando consideramos como as tecnologias de alto custo - sistemas computacionais, viagens aéreas globais, comunicações seguras - amplificam os poderes físicos dos corpos de homens de elite. 


\section{A dinâmica das masculinidades}

Apesar de há muito tempo reconhecida, a complexidade interna das masculinidades apenas gradualmente começa a se tornar uma questão de pesquisa. Como indicado em uma discussão anterior sobre o sujeito na prática de gênero, devemos reconhecer agora explicitamente a estratificação, a potencial contradição interna, dentre todas as práticas que constroem masculinidades. Tais práticas não podem ser lidas simplesmente como expressando uma masculinidade unitária. Elas podem, por exemplo, representar formações comprometidas por desejos contraditórios ou emoções, ou por resultados de cálculos incertos sobre os custos e os benefícios de diferentes estratégias de gênero.

Pesquisas com histórias de vida apontaram para uma outra dinâmica das masculinidades, a estrutura de um projeto. Masculinidades são configurações da prática que são construídas, reveladas e transformadas ao longo do tempo. Uma literatura menos abundante sobre masculinidade e envelhecimento, e uma maior produção sobre infância e juventude enfatizam essa questão. A análise cuidadosa das histórias de vida podem detectar compromissos contraditórios e transições institucionais que refletem diferentes masculinidades hegemônicas e também sustentam sementes de transformação.

As masculinidades hegemônicas tendem a envolver padrões específicos de divisão interna e conflito emocional, precisamente por sua associação com o poder generificado. Relações com os pais são mais comumente focos de tensão, dada a divisão sexual do trabalho no cuidado das crianças, a "cultura das longas horas" em profissões e gerenciamentos, e a preocupação dos pais ricos no manejo de sua riqueza. A ambivalência em direção aos projetos de mudança por parte das mulheres é comumente outro foco de tensão, levando a oscilações da aceitação e rejeição da igualdade de gênero por esses homens. Qualquer estratégia de manutenção do poder é mais comumente envolvida na desumanização de outros grupos e num correspondente definhamento da empatia e do envolvimento emocional subjetivo. ${ }^{168} \mathrm{Sem}$ tratar os homens privilegiados como objeto de pena, devemos reconhecer que a masculinidade hegemônica não necessariamente se traduz em uma experiência de vida satisfatória.

As transformações ao longo do tempo, na medida em que são certamente moldadas por contradições no seio das masculinidades, também podem ser intencionais. As crianças, assim como os adultos, têm a capacidade de desconstruir binarismos de gênero e criticar a masculinidade hegemônica, e essa capacidade é a base de muitas 
169 MEUSER, 2001

170 DEMETRIOU, 2001

171 COLLIER, 1998. intervenções educativas e programas de transformação. Ao mesmo tempo, titulares da masculinidade hegemônica não são necessariamente "entorpecidos culturais", eles podem tentar ativamente modernizar as relações de gênero e remodelar as masculinidades como parte de contratos. Um bom exemplo é o "novo gerenciamento público" em organizações do setor público, as quais rejeitam a burocracia do estilo antigo e acreditam em organizações "horizontais", em igualdade de oportunidades e em políticas de emprego familiares e amistosas. Mas mesmo a modernização das masculinidades talvez não resolva os problemas. Isso também, como argumentou Meuser, ${ }^{169}$ gera contradições que podem levar a transformações adicionais. Relações de gênero são sempre arenas de tensão. Um dado padrão de masculinidade é hegemônico enquanto fornece uma solução a essas tensões, tendendo a estabilizar o poder patriarcal ou reconstituí-lo em novas condições. Um padrão de práticas (isto é, uma versão de masculinidade) que forneceu soluções em condições anteriores, mas não em novas situações, é aberto ao questionamento - ele, de fato, será contestado.

Tal contestação ocorre continuamente, através dos esforços do movimento de mulheres (nos níveis local, regional e global), entre gerações em comunidades de imigrantes, entre modelos de masculinidade gerencial, entre rivais por autoridade política, entre reivindicadores por atenção na indústria de entretenimento, e assim por diante. A contestação é real, e a teoria de gênero não prevê qual prevalecerá - o processo é historicamente aberto. Em consequência, a hegemonia pode fracassar. O conceito de masculinidade hegemônica não se assenta em uma teoria da reprodução social.

Colocada de outra maneira, a conceitualização da masculinidade hegemônica deveria explicitamente reconhecer a possibilidade da democratização das relações de gênero e da abolição de desigualdades de poder, e não apenas a reprodução da hierarquia. Um movimento transicional nessa direção requer uma tentativa de estabelecer como hegemônica dentre os homens ("hegemonia interna" no sentido de Demetriou) ${ }^{170}$ uma versão da masculinidade aberta à igualdade com as mulheres. Nesse sentido, é possível definir uma masculinidade hegemônica completamente "positiva" (no sentido de Collier). ${ }^{171}$ A história recente mostrou a dificuldade de se atingir essa prática. Uma hegemonia positiva permanece, todavia, como uma estratégia-chave para os esforços contemporâneos de reforma. 


\section{Conclusão}

Os conceitos nas ciências sociais emergem como respostas a problemas práticos e intelectuais específicos, e são formulados em linguagens e estilos intelectuais específicos. Mas eles também têm a capacidade de viajar e talvez recebam novos significados enquanto viajam. Isso certamente aconteceu com o conceito de masculinidade hegemônica, o qual tem sido apropriado em diferentes campos, variando da educação à psicoterapia, à questão da violência e às relações internacionais. Algumas das suas ambiguidades despertaram uma reação crítica a vários usos que o conceito encontrou e às formas como foi flexibilizado em resposta a novos contextos.

Esse é talvez um problema geral sobre a conceitualização nas ciências sociais e nas humanidades. Como uma formulação teórica encontra aplicação em outros contextos e por outras mãos, o conceito deve se mutar - e deve fazê-lo em diferentes direções e em diferentes ambientes. Um conceito específico pode se transformar em uma generalização para se falar de algo, um estilo de análise ou uma figura característica em um argumento. Não há nada de errado nesse processo como tal - é a forma comum através da qual o conhecimento em ciências sociais e humanidades se desenvolve. Mas isso significa que os novos usos também devem estar abertos à crítica, pois talvez careçam da substância ou da justificação presente na formulação original.

Desse modo, ao mesmo tempo que acolhemos muitas das aplicações e das modificações do conceito de masculinidade hegemônica como contribuições à compreensão das dinâmicas de gênero, rejeitamos aqueles usos em que ficou implícito um tipo fixo de caráter ou um conjunto de traços tóxicos. Esses usos não são triviais - eles tentam nomear questões significantes sobre gênero, tais como a persistência da violência ou as consequências da dominação. Mas esses usos são feitos de uma maneira que entra em conflito com as análises da hegemonia nas relações de gênero e são, portanto, incompatíveis (e não apenas uma variação) tanto com as declarações iniciais como com os principais desenvolvimentos do conceito.

Uma análise renovada das masculinidades hegemônicas, do tipo sugerido anteriormente, tem uma relevância crescente no momento presente das políticas de gênero. Nos países ricos da metrópole global, o deslocamento do neoliberalismo (a agenda radical do mercado formulada nos anos 1970) para um neoconservadorismo (incluindo apelos populistas para religião, etnocentrismo e segurança) tornou a reação de gênero uma questão política e cultural muito importante. 
Nos países desenvolvidos, os processos de globalização abriram as ordens de gênero regionais e locais para novas pressões por transformações e também abriram caminhos para novas coalizões entre grupos de homens poderosos. Nas arenas globais das corporações transnacionais, das mídias e dos sistemas de segurança, novos padrões de hegemonia estão sendo forjados. A produção e a contestação da hegemonia em ordens de gênero historicamente mutáveis são um processo de enorme importância para o qual continuaremos precisando de ferramentas conceituais.

\section{Referências}

ALTMAN, D. Homosexual: Oppression and Liberation. Sydney, Australia: Angus and Robertson, 1972.

ARCHER, L. "Muslim Brothers, Black Lads, Traditional Asians: British Muslim Young Men's Constructions of Race, Religion and Masculinity." Feminism \& Psychology, v. 11, n. 1, p. 79-105, 2001.

BACA ZINN, M. "Chicano Men and Masculinity." Journal of Ethnic Studies, v. 10, n. 2, p. 29-44, 1982.

BARRETT, F. J. "The Organizational Construction of Hegemonic Masculinity: The Case of the U.S. Navy." Gender, Work and Organization, v. 3, n. 3, p. 129-142, 1996.

BELTON, R. J. The Beribboned Bomb: The Image of Woman in Male Surrealist Art. Calgary, Canada: University of Calgary Press, 1995.

BERG, L. D. "Masculinity, Place and a Binary Discourse of 'Theory' and 'Empirical Investigation' in the Human Geography of Aotearoa/New Zealand." Gender, Place and Culture, v. 1, n. 2, p. 245-260, 1994.

BIRD, S. R. "Welcome to the Men's Club: Homosociality and the Maintenance of Hegemonic Masculinity." Gender \& Society, v. 10, n. 2, p. 120-132, 1996.

BOURDIEU, P. Masculine Domination. Stanford, CA: Stanford University Press, 2001.

BRANNON, R. "The Male Sex Role: Our Culture's Blueprint of Manhood, and What It's Done for us Lately." In: DAVID, D. S.; BRANNON, R. (Ed.). The Forty-nine Percent Majority: The Male Sex Role. Reading, MA: Addington-Wesley, 1976.

BROD, H. The Making of Masculinities: The New Men's Studies. Boston: Allen and Unwin, 1987.

. "Some Thoughts on Some Histories of Some Masculinities: Jews and Other Others." In: DAVID, D. S.; BRANNON, R. (Ed.). Theorizing Masculinities. Thousand Oaks, CA: Sage, 1994.

BROKER, M. "'I may be a queer, but at least I am a man': Male Hegemony and Ascribed Versus Achieved Gender." In: 
BARKER, D. L.; ALLEN, S. (Ed.). Sexual Divisions and Society. London: Tavistock. 1976.

BROWN, D. "Complicity and Reproduction in Teaching Physical Education." Sport, Education and Society, v. 4, n. 2, p. 143-159, 1999.

BUFKIN, J. L. "Bias Crime as Gendered Behavior." Social Justice, v. 26, n. 1, p. 155-176, 1999.

BURGESS, I.; EDWARDS, A.; SKINNER, J. "Football Culture in an Australian School Setting: The Construction of Masculine Identity." Sport, Education and Society, v. 8, n. 2, p. 199212, 2003.

CAMPBELL, H. "The Glass Phallus: Pub(lic) Masculinity and Drinking in Rural New Zealand." Rural Sociology, v. 65, n. 4, p. 562-581, 2000

CARRIGAN, T.; CONNELL, R. W.; LEE, J. "Toward a New Sociology of Masculinity." Theory and Society, v. 14, n. 5, p. 551604, 1985.

CAVENDER, G. "Detecting Masculinity." In: FERRELL, J.; WEBSDALE, N. (Ed.). Making Trouble: Cultural Constructions of Crime, Deviance and Control. New York: Aldine de Gruyter, 1999.

CHENG, C. "'We choose not to compete': The 'Merit' Discourse in the Selection Process, and Asian and Asian American Men and their Masculinity." In: CHENG, C. (Ed.). Masculinities in Organizations. Thousand Oaks, CA: Sage, 1996.

COCKBURN, C. Brothers: Male Dominance and Technological Change. London: Pluto, 1983.

. In the Way of Men: Men's Resistance to Sex Equality in Organizations. London: Macmillan, 1991.

COLLIER, R. Masculinities, Crime and Criminology: Men, Heterosexuality and the Criminal(ised) Other. London: Sage, 1998.

COLLINSON, D.; HEARN, J. "Naming Men as Men: Implications for Work, Organization and Management." Gender, Work and Organization, v. 1, n. 1, p. 2-22, 1994.

COLLINSON, D.; KNIGHTS, D.; COLLINSON, M. Managing to Discriminate. London: Routledge, 1990.

CONNELL, R. W. Ruling Class, Ruling Culture. Cambridge, UK: Cambridge University Press, 1977. . "Class, Patriarchy, and Sartre's Theory of Practice." Theory and Society, v. 11, p. 305-320, 1982. Which Way is up? Essays on Sex, Class and Sulture. Sydney, Australia: Allen and Unwin, 1983. Gender and Power. Sydney, Australia: Allen and Unwin, 1987.

. "An Iron Man: The Body and some Contradictions of Hegemonic Masculinity." In: MESSNER, M.; SABO, D. (Ed.). Sport, Men and the Gender Order. Champaign, IL: Human Kinetics, Books, 1990. 
Masculinities. Cambridge, UK: Polity Press, 1995.

"Masculinities and Globalization." Men and Mascu-

linities, v. 1, n. 1, p. 3-23, 1998.

Gender. Cambridge, UK: Polity Press, 2002.

"Masculinities, Change and Conflict in Global Society:

Thinking about the Future of Men's Studies." Journal of Men's

Studies, v. 11, n. 3, p. 249-266, 2003.

. "Globalization, Imperialism, and Masculinities." In:

KIMMEL, M. S.; HEARN, J.; CONNELL, R. W. (Ed.). Handbook of Studies on Men \& Masculinities. Thousand Oaks, CA: Sage, 2005.

CONNELL, R. W. et al. Making the Difference: Schools, Families and Social Division. Sydney, Australia: Allen and Unwin, 1982.

CONNELL, R. W.; WOOD, J. "Globalization and Business Masculinities." Men and Masculinities, v. 7, n. 4, p. 347364, 2005.

CONSALVO, M. "The Monsters Next Door: Media Constructions of Boys and Masculinity." Feminist Media Studies, v. 3, n. 1, p. 27-46, 2003.

DASGUPTA, R. "Performing Masculinities? The 'Salaryman' at Work and Play." Japanese Studies, v. 20, n. 2, p. 189-200, 2000.

DAVIS, A. Women, Race, and Class. New York: Vintage, 1983.

DEMETRIOU, D. Z. "Connell's Concept of Hegemonic Masculinity: A Critique." Theory and Society, v. 30, n. 3, p. 337-361, 2001.

DENBOROUGH, D. "Step by Step: Developing Respectful and Effective Ways of Working with Young Men to Reduce Violence." In: McLEAN, C.; CAREY, M.; WHITE, C. (Ed.). Men's Ways of Being. Boulder, CO: Westview, 1996.

DINGES, M.; RÜNDAL, E.; BAUER, D. "Programm.” In: PROGRAM FOR THE HEGEMONIALE MÄNNLICHKEITEN CONFERENCE, 24-26 June 2004, Stuttgart, Germany.

DONALDSON, M. Time of Our Lives: Labor and Love in the Working Class. Sydney, Australia: Allen and Unwin, 1991.

"What is Hegemonic Masculinity?" Theory and Society, v. 22, p. 643-657, 1993.

DONALDSON, M.; POYNTING, S. "The Time of their Lives: Time, Work and Leisure in the Daily Lives of Ruling-class Men." In: HOLLIER, N. (Ed.). Ruling Australia: The Power, Privilege \& Politics of the New Ruling Class. Melbourne: Australian Scholarly, 2004.

EISENSTEIN, Z. R. Capitalist Patriarchy and the Case for Socialist Feminism. New York: Monthly Review Press, 1979.

FERGUSON, H. "Men and Masculinities in Late-modern Ireland." In: PEASE, B.; PRINGLE, K. (Ed.). A Man's World? Changing Men's Practices in a Globalized World. London: Zed Books, 2001. 
FREUD, Sigmund. From the History of an Infantile Neurosis. Complete Psychological Works. Standard ed. London: Hogarth, 1955. v. 17.

FRIEDMAN, R. M.; LERNER, L. "Toward a Newpsychology of Men: Psychoanalytic and Social Perspectives." Psychoanalytic Review, v. 73, n. 4, 1986. Special issue.

GERSCHICK, T. J.; MILLER, A. S. "Gender Identities at the Crossroads of Masculinity and Physical Disability." Masculinities, v. 2, n. 1, p. 34-55, 1994.

GOODE, W. "Why Men Resist." In: THORNE, B.; YALOM, M. (Ed.). Rethinking the Family: Some Feminist Questions. New York: Longman, 1982.

GUTMANN, M. C. The Meanings of Macho: Being a Man in Mexico City. Berkeley: University of California Press, 1996.

HACKER, H. M. "The New Burdens of Masculinity." Marriage and Family Living, v. 19, n. 3, p. 227-233, 1957.

HALBERSTAM, J. Female Masculinity. Durham, NC: Duke University Press, 1998.

HANKE, R. "Redesigning Men: Hegemonic Masculinity in Transition." In: CRAIG, S. (Ed.). Men, Masculinity, and the Media. Newbury Park, CA: Sage, 1992.

HAWKESWORTH, M. "Confounding Gender." Signs: Journal of Women in Culture and Society, v. 22, n. 3, p. 649-685, 1997.

HEARN, J. "Is Masculinity Dead? A Critique of the Concept of Masculinity/Masculinities." In: MAC AN GHAILL, M. (Ed.). Understanding Masculinities: Social Relations and Cultural Arenas. Buckingham, UK: Open University Press, 1996.

"From Hegemonic Masculinity to the Hegemony of Men." Feminist Theory, v. 5, n. 1, p. 49-72, 2004.

HERDT, G. H. Guardians of the Flutes: Idioms of Masculinity. New York: McGraw-Hill, 1981.

HIGATE, P. R. Military Masculinities: Identity and the State. London: Praeger, 2003.

HOCHSCHILD, A. The Second Shift: Working Parents and the Revolution at Home. New York: Viking, 1989.

HOLTER, $\varnothing$. G. Gender, Patriarchy and Capitalism: A Social Forms Analysis. Oslo, Norway: University of Olso, 1997.

Can Men do It? Men and Gender Equality: The Nordic

Experience. Copenhagen, Denmark: Nordic Council of Ministers, 2003.

HOOKS, B. Feminist Theory: From Margin to Center. Boston: South End, 1984.

HOOPER, C. "Masculinist Practices and Gender Politics: The Operation of Multiple Masculinities in International Relations." In: ZALEWSKI, M.; PARPART, J. (Ed.). The "Man" Question in International Relations. Boulder, CO: Westview, 1998. 
"Masculinities in Transition: The Case of Globalization." In: MARCHAND, M. H.; RUNYAN, A. S. (Ed.). Gender and Global Restructuring, London: Routledge, 2000.

Manly States: Masculinities, International Relations, and Gender Politics. New York: Columbia University Press, 2001.

HUNT, P. Gender and Class Consciousness. London: Macmillan, 1980.

ISHII-KUNTZ, M. "Balancing Fatherhood and Work: Emergence of Diverse Masculinities in Contemporary Japan." In: ROBERSON, J. E.; SUZUKI, N. (Ed.). Men and Masculinities in Contemporary Japan. London: Routledge Curzon, 2003.

JANSEN, S. C.; SABO, D. "The Sport-war Metaphor: Hegemonic Masculinity, the Persian-Gulf War, and the New World Order." Sociology of Sport Journal, v. 11, n. 1, p. 1-17, 1994.

JEFFERSON, T. "Theorizing Masculine Subjectivity." In: NEWBURN, T.; STANKO, E. A. (Ed.). Just Boys doing Business? Men, Masculinities and Crime. London: Routledge, 1994. "Subordinating Hegemonic Masculinity." Theoretical Criminology, v. 6, n. 1, p. 63-88, 2002.

KESSLER, S. J. et al. Ockers and Disco-maniacs. Sydney, Australia: Inner City Education Center, 1982.

KIMMEL, M. S. "Rethinking 'Masculinity': New Directions in Research." In: KIMMEL, M. S. (Ed.). Changing Men: New Directions in Research on Men and Masculinity. Newbury Park, CA: Sage, 1987.

"Globalization and Its Mal(e)contents: The Gendered Moral and Political Economy of Terrorism." In: KIMMEL, M. S.; HEARN, J.; CONNELL, R. W. (Ed.). Handbook of Studies on Men \& Masculinities. Thousand Oaks, CA: Sage, 2005.

KIMMEL, M. S.; MAHLER, M. "Adolescent Masculinity, Homophobia, and Violence: Random School Shootings, 1982-2001." American Behavioral Scientist, v. 46, n. 10, p. 1439-1458, 2003.

KUPERS, T. A. Revisioning Men's Lives: Gender, Intimacy, and Power. New York: Guilford, 1993.

LEA, S.; AUBURN, T. "The Social Construction of Rape in the Talk of a Convicted Rapist." Feminism \& Psychology, v. $11, \mathrm{n}$. 1, p. 11-33, 2001.

LIGHT, R.; KIRK, D. "High School Rugby, the Body and the Reproduction of Hegemonic Masculinity." Sport, Education and Society, v. 5, n. 2, p. 163-176, 2000.

MAC AN GHAILL, M. The Making of Men: Masculinities, Sexualities and Schooling. Buckingham, UK: Open University Press, 1994.

MacINNES, J. The End of Masculinity: The Confusion of Sexual Genesis and Sexual Difference in Modern Society. Buckingham, UK: Open University Press, 1998. 
MARTIN, P. Y. "Why can't a Man be more like a Woman? Reflections on Connell's Masculinities." Gender \& Society, v. 12, n. 4, p. 472-474, 1998.

. 'Mobilizing Masculinities': Women's Experiences of Men at Work." Organizations, v. 8, n. 4, p. 587-618, 2001.

MARTINO, W. "Boys and Literacy: Exploring the Construction of Hegemonic Masculinities and the Formation of Literate Capacities for Boys in the English Classroom." English in Australia, v. 112, p. 11-24, 1995.

McMAHON, A. "Male Readings of Feminist Theory: The Psychologization of Sexual Politics in the Masculinity Literature." Theory and Society, v. 22, n. 5, p. 675-695, 1993.

MESSERSCHMIDT, J. W. Masculinities and Crime: Critique and Reconceptualization of Theory. Lanham, MD: Rowman \& Littlefield, 1993.

"Managing to Kill: Masculinities and the Space Shuttle Challenger Explosion." Masculinities, v. 3, n. 4, p. 1-22, 1995.

Crime as Structured Action: Gender, Race, Class and Crime in the Making. Thousand Oaks, CA: Sage, 1997. . Nine Lives: Adolescent Masculinities, the Body, and Violence. Boulder, CO: Westview, 2000. Flesh \& Blood: Adolescent Gender Diversity and Violence. Lanham, MD: Rowman \& Littlefield, 2004. . "Men, Masculinities, and Crime." In: KIMMEL, M. S.; HEARN, J.; CONNELL, R. W. (Ed.). Handbook of Studies on Men \& Masculinities. Thousand Oaks, CA: Sage, 2005.

MESSNER, M. A. Power at Play: Sports and the Problem of Masculinity. Boston: Beacon, 1992. Politics of Masculinities: Men in Movements. Thousand Oaks, CA: Sage, 1997. Taking the Field: Women, Men, and Sport. Minneapolis: University of Minnesota Press, 2002.

MESSNER, M. A.; SABO, D. (Ed.). Sport, Men, and the Gender Order: Critical Feminist Perspectives. Champaign, IL: Human Kinetics Books, 1990.

MEUSER, M. “'This doesn't Really Mean she's holding a Whip': Transformation of the Gender Order and the Contradictory Modernization of Masculinity." Diskurs, v. 1, p. 44-50, 2001. . "Modernized Masculinities? Continuities, Challenges and Changes in Men's Lives." In: ERV $\varnothing$, S.; JOHANNSON, T. (Ed.). Amongmen: Moulding Masculinities. Aldershot, UK: Ashgate, 2003.

MEUSER, M.; BEHNKE, C. "Tausendundeine Männlichkeit? Männlichkeitsmuster und Socialstrukturelle Einbindungen". Widersprüche, v. 67, p. 7-25, 1998.

MIELI, M. Homosexuality and Liberation: Elements of a Gay Critique. Translated by D. Fernbach. London: Gay Men's Press, 1980. 
MITTELMAN, J. H. Whither Globalization? The Vortex of Knowledge and Ideology. London: Routledge, 2004.

MORIN, S. F.; GARFINKLE, E. M. "Male Homophobia." Journal of Social Issues, v. 34, n. 1, p. 29-47, 1978.

MORRELL, R. "Of Boys and Men: Masculinity and Gender in Southern African Studies." Journal of Southern African Studies, v. 24, n. 4, p. 605-630, 1998.

MORRELL, R.; SWART, S. "Men in the Third World: Postcolonial Perspectives on Masculinity." In: KIMMEL, M. S.; HEARN, J.; CONNELL, R. W. (Ed.). Handbook of Studies on Men \& Masculinities. Thousand Oaks, CA: Sage, 2005.

MORRIS, C.; EVANS, N. “'Cheese Makers are Always Women': Gendered Representations of Farm Life in the Agricultural Press." Gender, Place and Culture, v. 8, n. 4, p. 375-390, 2001.

MOSHER, D. L.; TOMKINS, S. S. Scripting the Macho Man: Hypermasculine Socialization and Enculturation. Journal of Sex Research, v. 25, n. 1, p. 60-84, 1988.

NAMASTE, V. K. Invisible Lives: The Erasure of Transsexual and Transgendered People. Chicago: University of Chicago Press, 2000.

NEWBURN, T.; STANKO, E. A. Just Boys doing Business? Men, Masculinities, and Crime. New York: Routledge, 1994.

PEASE, B.; PRINGLE, K. (Ed.). A Man's World? Changing Men's Practices in a Globalized World. London: Zed Books, 2001.

PETERSEN, A. Unmasking the Masculine: "Men" and "Identity" in a Sceptical Age. London: Sage, 1998.

"Research on Men and Masculinities: Some Implications of Recent Theory for Future Work." Men and Masculinities, v. 6, n. 1, p. 54-69, 2003.

PLECK, J. The Myth of Masculinity. Cambridge, MA: MIT Press, 1981.

PLUMMER, K. (Ed.). The Making of the Modern Homosexual. London: Macmillan, 1981.

POYNTING, S.; NOBLE, G.; TABAR, P. "Intersections" of Masculinity and Ethnicity: A Study of Male Lebanese Immigrant Youth in Western Sydney. University of Western Sydney, 2003. Unpublished manuscript.

ROBERTS, P. "Social Control and the Censure(s) of Sex." Crime, Law and Social Change, v. 19, n. 2, p. 171-186, 1993.

ROPER, M. Masculinity and the British Organization Man Since 1945. Oxford, UK: Oxford University Press, 1994.

RUBIN, H. Self-made Men: Identity and Embodiment Among Transsexual Men. Nashville, TN: Vanderbilt University Press, 2003.

SABO, D.; GORDON, D. F. (Ed.). Men's Health and Illness: Gender, Power and the Body. Thousand Oaks, CA: Sage, 1995. 
SABO, D.; JANSEN, S. C. "Images of Men in Sport Media: The Social Reproduction of Gender Order." In: CRAIG, S. (Ed.). Men, Masculinity, and the Media. Newbury Park, CA: Sage, 1992.

SALISBURY, J.; JACKSON, D. Challenging Macho Values: Practical Ways of Working with Adolescent Boys. Washington, DC: Falmer, 1996.

SCHWALBE, M. "Male Supremacy and the Narrowing of the Moral Self." Berkeley Journal of Sociology, v. 37, p. 29-54, 1992.

SCOTT, J. W. "Comment on Hawkesworth's 'Confounding Gender'." Signs: Journal of Women in Culture and Society, v. 22, n. 3, p. 697-702, 1997.

SEGAL, L. Slow Motion: Changing Masculinities, Changing Men. London: Virago, 1990.

SKELTON, A. "On Becoming a Male Physical Education Teacher: The Informal Culture of Students and the Construction of Hegemonic Masculinity." Gender and Education, v. 5, n. 3, p. 289-303, 1993.

SNODGRASS, J. (Ed.). For Men against Sexism: A Book of Readings. Albion, CA: Times Change Press, 1977.

STOLLER, R. J. Sex and Gender: On the Development of Masculinity and Femininity. New York: Science House, 1968.

TAGA, F. "Rethinking Male Socialization: Life Histories of Japanese Male Youth." In: LOUIE, K.; LOW, M. (Ed.). Asian Masculinities. London: Routledge Curzon, 2003.

THORNE, B. Gender Play. New Brunswick, NJ: Rutgers University Press, 1993.

THORNTON, M. "Hegemonic Masculinity and the Academy." International Journal of the Sociology of Law, v. 17, p. 115-130, 1989.

TOLSON, A. The Limits of Masculinity. London: Tavistock, 1977.

TOMSEN, S. Hatred, Murder and Male Honour: Anti-homosexual Homicides in New South Wales, 1980-2000. Canberra: Australian Institute of Criminology, 2002. v. 43.

VALDÉS, T.; OLAVARRÍA, J. "Ser hombre en Santiago de Chile: a pesar de todo, un mismo modelo." In: VALDÉS, T.; OLAVARRÍA, J. (Ed.). Masculinidades y equidad de género en América Latina. Santiago, Chile: FLACSO/UNFPA, 1998.

WAJCMAN, J. Managing Like a Man: Women and Men in Corporate Management. Sydney, Australia: Allen and Unwin, 1999.

WALBY, S. Gender Transformations. London: Routledge, 1997.

WARREN, S. "Who do these Boys think they are? An Investigation Into the Construction of Masculinities in a Primary Classroom." International Journal of Inclusive Education, v. 1, n. 2, p. 207-222, 1997. 
WETHERELL, M.; EDLEY, N. "Negotiating Hegemonic Masculinity: Imaginary Positions and Psycho-discursive Practices." Feminism and Psychology, v. 9, n. 3, p. 335-356, 1999.

WHITEHEAD, S. M. "Hegemonic Masculinity Revisited." Gender, Work, and Organization, v. 6, n. 1, p. 58-62, 1998.

. Men and Masculinities: Key Themes and New Directions. Cambridge, UK: Polity, 2002.

WILLIS, P. Learning to Labor: How Working Class Kids Get Working Class Jobs. Farnborough, UK: Saxon House, 1977.

ZARETSKY, E. "Male Supremacy and the Unconscious." Socialist Revolution, v. 4, p. 7-55, 1975.

Tradução: Felipe Bruno Martins Fernandes

\section{Hegemonic Masculinity: Rethinking the Concept}

Abstract: The concept of hegemonic masculinity has influenced gender studies across many academic fields but has also attracted serious criticism. The authors trace the origin of the concept in a convergence of ideas in the early 1980s and map the ways it was applied when research on men and masculinities expanded. Evaluating the principal criticisms, the authors defend the underlying concept of masculinity, which in most research use is neither reified nor essentialist. However, the criticism of trait models of gender and rigid typologies is sound. The treatment of the subject in research on hegemonic masculinity can be improved with the aid of recent psychological models, although limits to discursive flexibility must be recognized. The concept of hegemonic masculinity does not equate to a model of social reproduction; we need to recognize social struggles in which subordinated masculinities influence dominant forms. Finally, the authors review what has been confirmed from early formulations (the idea of multiple masculinities, the concept of hegemony, and the emphasis on change) and what needs to be discarded (onedimensional treatment of hierarchy and trait conceptions of gender). The authors suggest reformulation of the concept in four areas: a more complex model of gender hierarchy, emphasizing the agency of women; explicit recognition of the geography of masculinities, emphasizing the interplay among local, regional, and global levels; a more specific treatment of embodiment in contexts of privilege and power; and a stronger emphasis on the dynamics of hegemonic masculinity, recognizing internal contradictions and the possibilities of movement toward gender democracy.

Keywords: Masculinity; Hegemony; Gender; Social Power; Agency; Embodiment; Globalization. 